Article

\title{
Sustainable EOQ under Lead-Time Uncertainty and Multi-Modal Transport
}

\author{
Soon-Kyo Lee ${ }^{1}$, Seung Ho Yoo ${ }^{2, *}$ and Taesu Cheong ${ }^{1, *}$ \\ 1 School of Industrial Management Engineering, Korea University, Seoul 02841, Korea; myeva@korea.ac.kr \\ 2 Division of Business Administration, Sunmoon University, Asan, Chungnam 31460, Korea \\ * Correspondences: tcheong@korea.ac.kr (T.C.); shy1228@sunmoon.ac.kr (S.H.Y.); \\ Tel.: +82-2-3290-3382 (T.C.); +82-41-530-2536 (S.H.Y.)
}

Academic Editor: Ilkyeong Moon

Received: 16 December 2016; Accepted: 16 March 2017; Published: 22 March 2017

\begin{abstract}
In this paper, we examine a sustainable economic order quantity (S-EOQ) problem with a stochastic lead-time and multi-modal transportation options. With the S-EOQ, decisions of order quantities, as well as a reorder point could be influenced by various factors, including unit price, stock-out cost, lead-time variability and emission costs. For a better understanding, we present a mathematical model of the concomitant S-EOQ problem and, using numerical experiments, explore various scenarios to determine the effects of incorporating sustainability considerations into the traditional inventory model on operational decisions including the choice of transportation modal combination and the sourcing decisions
\end{abstract}

Keywords: EOQ; sustainability; lead-time uncertainty; multimodal

\section{Introduction}

According to the World Trade Report 2015 [1], international trade has been growing at a modest pace in recent years, and the exports of developing and emerging countries in particular have been growing faster than those of developed ones. Effective international trading and sourcing have become essential for competing on price in commodity markets. As the amount of international trade grows, transportation is regarded as a major driver of the globalization of supply chains, and subsequently, the distances managed by logistics have become much longer than before. Furthermore, because of the centralization of production, many companies use long-distance sourcing so that they can gain a competitive advantage on price.

However, growing international trade has exposed the now globalized supply chains to many types of risks, and the risks associated with long-distance sourcing have further increased due to longer and, therefore, more variable lead-times. Furthermore, the increase in transportation due to international trade causes much pollution. According to Sources of Greenhouse Gas Emissions [2] by the EPA (U.S. Environmental Protection Agency) in 2014, 26 percent of total U.S. greenhouse gas emissions by the economic sector derived from the transportation area. The IPCC report [3] also states that the greenhouse gas emissions caused by transportation are mainly from the burning of fossil fuels in cars, trucks, ships, trains and planes. Over 90 percent of the fuel used for transportation is petroleum-based, including gasoline and diesel. Recently, external emission costs $[4,5]$ have become an important issue for supply chain management because of several environment conservation agreements, such as the Kyoto Protocol and the Paris Agreement. Due to increasing concerns about the environment and sustainability, managing transportation costs in inventory and supply chain management has become more important than ever.

In this paper, we examine a single-product replenishment problem, which takes both lead-time uncertainty and multi-modal transports into account. We note that lead-time uncertainty and 
multi-modal transportation are two major characteristics of international trades and global supply chains. Specifically, we are interested in developing a mathematical model of the replenishment problem incorporating sustainability considerations, which has become essential as international trading and sourcing have grown, to reflect the growing recognition of the external effects of transport and subsequently more sustainable use of transport modes. Through the replenishment decision models, we intend to address the effects of sustainability considerations on operational decisions, such as replenishment decisions, choices of transportation modalities and sourcing decisions (specifically, domestic sourcing vs. international sourcing).

The remainder of the paper is as follows. Section 2 reviews the previous studies relevant to the problem under consideration. Section 3 provides a description of the sustainable EOQ (S-EOQ) problem with lead-time uncertainty and multi-modal transportation options and proposes its mathematical programming model. In Section 4, we perform numerical experiments and a sensitivity analysis and discuss the managerial insights gained. Finally, we conclude the discussions in Section 5.

\section{Literature Review}

In this section, we mainly review EOQ models incorporating environmental and sustainability factors and their extensions considering either uncertain lead-times or transportation mode selections. Turkay [6] extends the conventional EOQ model to one incorporating sustainability considerations by adding environmental criteria and evaluates five different approaches including direct accounting, carbon taxes, direct caps, cap and trades and carbon offsets. Hua et al. [7] consider a sustainable EOQ model using cap-and-trade approaches and examine the relation between the order size of carbon cap and carbon price. Their model, unlike ours, does not include transportation mode choices in the decision model. Bonney and Jaber [8] also develop a model that extends the EOQ to include some environmental factors. However, their model has some shortcomings, including no calculation of the social costs of vehicle emissions and no examination of the effect of transportation mode selection. Wahab et al. [9] partly examine the impact of considering the environment on the optimal production-shipment policy for items of imperfect quality in a two-level supply chain. In the model, they divide $\mathrm{CO}_{2}$ emission costs into fixed and variable costs. They compare the case with and without environmental effects and evaluate how the total expected costs and optimal number of shipments change depending on the environmental considerations applied. However, they ignore the selection of transportation mode in the two-level international supply chain. Bouchery et al. [10] reformulate the conventional EOQ model as a multi-objective problem because of the difficulty of developing a single objective problem that considers all aspects of sustainable issues. Moon et al. [11] present a bi-objective mixed-integer linear programming model in a multi-period planning horizon with inaccurate information on raw material resources under a carbon emission constraint. However, the model does not consider combination of transport modes and the length of transportation routes, which are different from ours. Lastly, Battini et al. [12] recently proposed a sustainable EOQ model, from which we extend in this paper. They investigate the environmental impact of inventory and transportation in the traditional EOQ model by additionally incorporating the sustainability factors into the replenishment model. For further information, we refer readers to a survey paper [13], which comprehensively explores the evolution of EOQ models, including lot-sizing research on environmental sustainability.

None of the works reviewed above incorporate lead-time uncertainty, which is one of the primary sources of uncertainty, especially in international supply chains. There is limited research on EOQ models, including both lead-time uncertainty and sustainability considerations. Digiesi et al. [14] develop a sustainable EOQ model, which, like ours, incorporates lead-time uncertainty. They identify the optimal order quantity and modal selection with respect to the loss factor of modals with different coefficients of variance. However, the paper compares only mono-modal transportation options.

When it comes to multi-modal transportation options, Winebrake et al. [15] propose an intermodal network model called GIFTto help evaluate the costs, the delivery times and the environmental 
and energy impacts associated with mono-modal and intermodal freight transport. In the paper, they perform some numerical experiments with the same source and destination, but different routes. They show that the decision made varies depending on which decision criterion, such as the minimization of carbon dioxide, cost or time, is important to the decision maker. In this paper, we examine multi-modal freight transport with lead-time uncertainty.

\section{Sustainable EOQ Model with Lead-Time Uncertainty and Multi-Modality}

To understand the effects of lead-time uncertainty with multi-modal shipment options on S-EOQ decisions under the $(Q, R)$ policy, we present the mathematical formulation of the concomitant S-EOQ problem. Before introducing the model formulation, all of the parameters and decision variables used in this paper are given as follows.

Decision variables:

$Q \quad$ order quantity

$Q_{r} \quad$ reorder point

Sets and parameters:

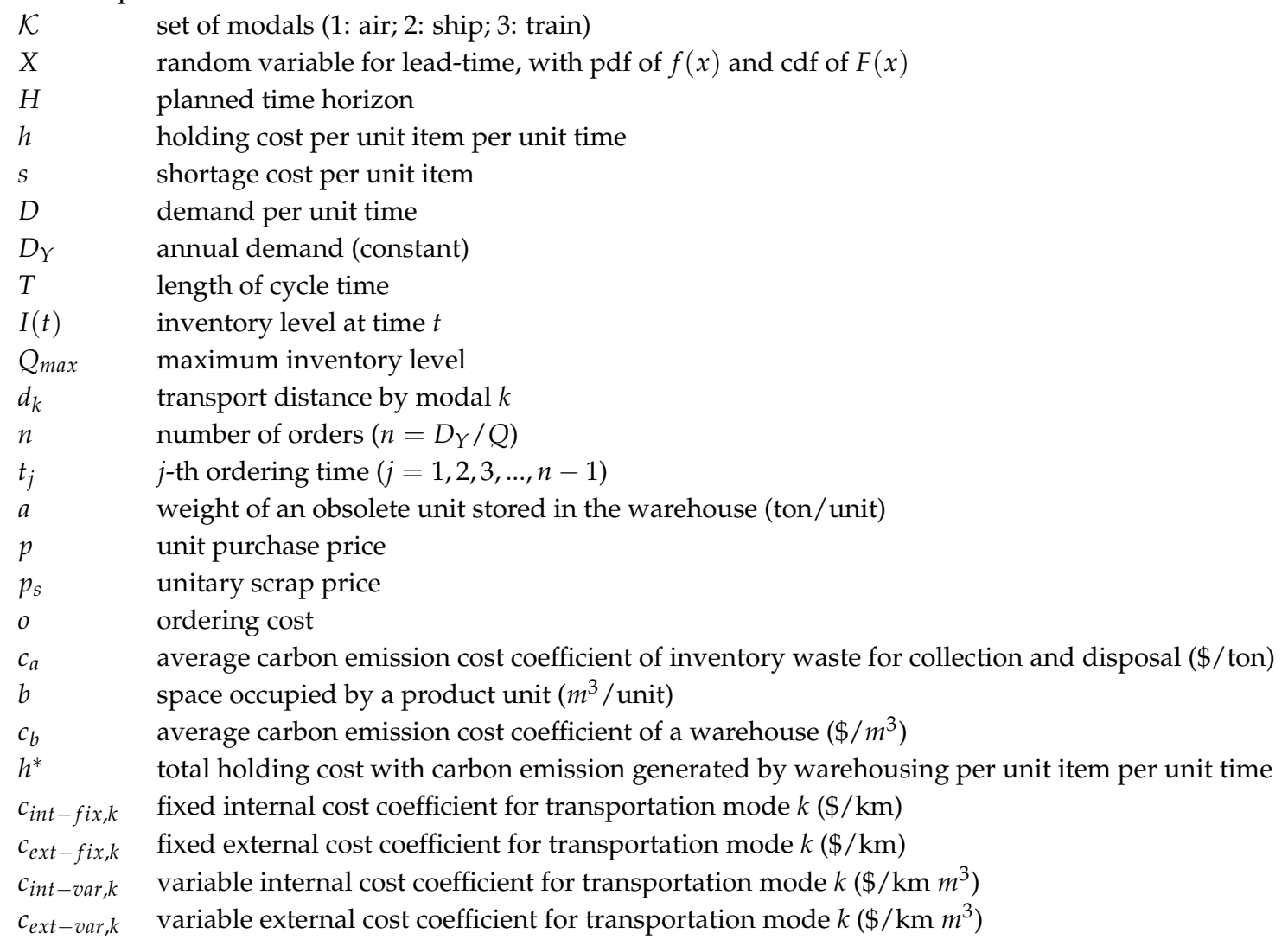

In this paper, we assume that the annual demand is deterministic and constant as in the traditional EOQ model. Thus, it is assumed that $\frac{d I(t)}{d t}=-D$ holds throughout the paper. We also assume that the initial inventory level $I(0)$ is equal to $Q_{\max }$ as illustrated in Figure 1. Given those assumptions, we now present the problem formulation for the S-EOQ model.

The total annual cost of the model $(\mathcal{T C})$ consists of the purchasing cost, ordering cost $(\mathcal{O C})$, holding cost $(\mathcal{H C})$, shortage cost $(\mathcal{S C})$ and transportation cost $(\mathcal{T P C})$. Since the annual purchasing cost is independent of the decision variables, for simplicity, it is henceforth excluded from the total annual cost calculation as presented in Equation (1).

$$
\mathcal{T C}\left(Q, Q_{r}\right)=\mathcal{O C}(Q)+\mathcal{H C}\left(Q, Q_{r}\right)+\mathcal{S C}\left(Q, Q_{r}\right)+\mathcal{T} \mathcal{P C}\left(Q, Q_{r}\right)
$$


From a sustainability point of view, the total annual cost $\mathcal{T C}$ in this model includes economic costs associated with environmental and sustainability effects when we calculate holding cost $\mathcal{H C}$ and transportation cost $\mathcal{T P C}$ due to the fact that storage and transportation of goods within supply chains are major causes of environmental damage in modern value-added processes. According to Dhooma and Baker [16], carbon emission related to warehousing is a significant factor because of the considerable energy requirements for heating, cooling, materials handling equipment, and so on. Furthermore, transportation activities are responsible for around $25 \%$ of the world's energy use and for almost $22 \%$ of global energy emissions [4]. The incorporation of environmental costs in the calculation of both holding and transportation costs will be discussed with details in the following subsections.

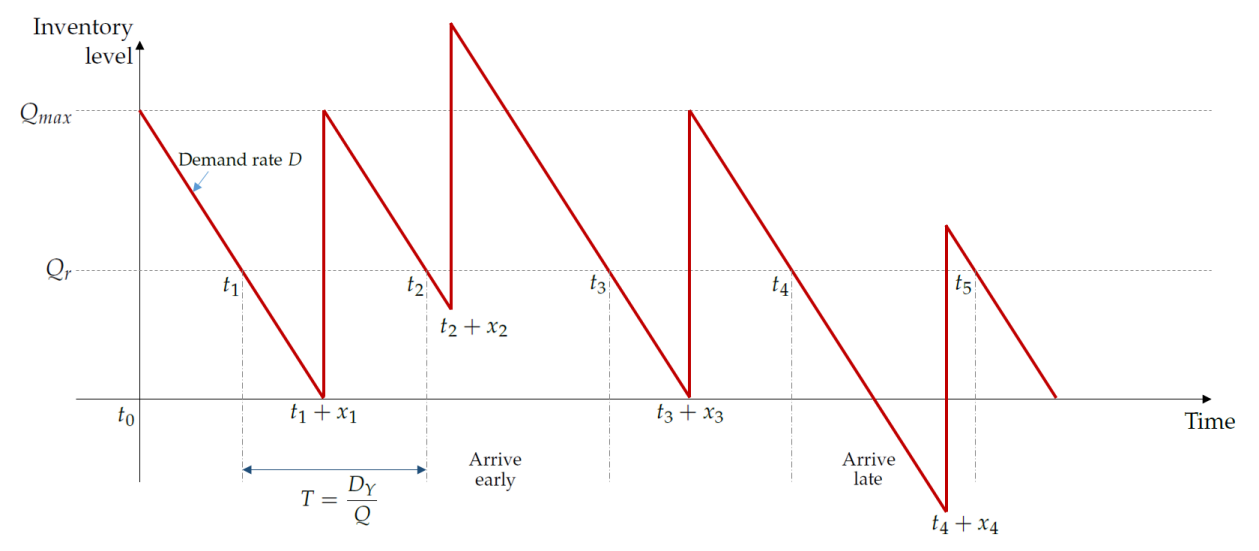

Figure 1. Example of inventory profile under lead-time uncertainty.

We now take a look at the details of each cost component. For a better understanding of them, we first illustrate the structure of the inventory profile and its changes over time as shown in Figure 1 and then explain the possible cases resulting from the lead-time uncertainty. According to the well-known $(Q, R)$ policy, an order of amount $Q$ is placed whenever the inventory level drops below the reorder point $Q_{r}$ and the order arrives after the lead-time $X$, which is uncertain in this paper. As mentioned earlier, we assume that the inventory level drops by the constant rate of $D$. Suppose that the lead-time of an order is $x_{1}$, and an order placed at $t_{1}$ arrives at $t_{1}+x_{1}$. The lead-time uncertainty creates two possible cases. Consider the case of an order placed at $t_{2}$ and with a lead-time $x_{2}$, which is less than the average lead-time. Assume it arrives at $t_{2}+x_{2}$ before the inventory level drops below zero. This case obviously incurs a higher holding cost. Consider the contrasting case of an order placed at $t_{4}$ and with a lead-time $x_{4}$, which is more than the average lead-time. Assume it arrives at $t_{4}+x_{4}$ after the inventory level drops below zero. This can clearly incur higher stock-out costs. Thus, a supply chain with lead-time uncertainty may have higher total expected annual cost than the one with a deterministic lead-time. Based on the discussion above, the inventory level at time $t$ over a cycle $T=\frac{D_{Y}}{Q}$ can be expressed as Equation (2):

$$
I(t)= \begin{cases}Q_{r}-D\left(t-t_{j}\right), & t_{j} \leq t \leq t_{j}+x \\ Q+Q_{r}-D\left(t-t_{j}\right), & t_{j}+x \leq t \leq t_{j+1}\end{cases}
$$

We remark that Equation (2) is divided into two parts based on the time at which the order placed at $t_{j}$ arrives.

We now examine each cost component in detail.

\subsection{Ordering Cost $\mathcal{O C}$}

The annual ordering cost $(\mathcal{O C})$ is simply calculated as the number of orders multiplied by the (fixed) ordering cost per order, which is: 


$$
\mathcal{O C}(Q)=o \times \frac{D_{Y}}{Q}
$$

\subsection{Holding Cost $\mathcal{H C}$}

Due to the lead-time uncertainty, the calculation of the annual holding costs $(\mathcal{H C})$ is not straightforward, and hence, we divide the calculation into two cases depending on the inventory level when a new order arrives.

(a) The case when the lead-time is less than the expected lead-time:

We let $H_{a}\left(Q, Q_{r}, x\right)$ be the holding cost per cycle when the order replenishment policy follows $\left(Q, Q_{r}\right)$. The lead-time $x$ is less than the expected lead-time. By referring to Figure 1 and especially the interval between $t_{2}$ and $t_{3}$, the holding cost per cycle can be expressed as in Equation (4).

$$
\begin{aligned}
H_{a}\left(Q, Q_{r}, x\right) & =h\left[\int_{t_{j}}^{t_{j}+x} I(t) d t+\int_{t_{j}+x}^{t_{j+1}} I(t) d t\right] \\
& =h\left[\int_{t_{j}}^{t_{j}+x}\left(Q_{r}-D\left(t-t_{j}\right)\right) d t+\int_{t_{j}+x}^{t_{j+1}}\left(Q+Q_{r}-D\left(t-t_{j}\right)\right) d t\right] \\
& =\frac{h}{2 D}\left[\left(Q_{r}+Q-D x\right)^{2}-\left(Q_{r}-D x\right)^{2}\right]
\end{aligned}
$$

(b) The case when the lead-time is greater than the expected lead-time:

In this case, the lead-time $x$ is more than the expected lead-time. Refer to the interval between $t_{4}$ and $t_{5}$. The corresponding holding $\operatorname{cost} H_{b}\left(Q, Q_{r}, x\right)$ can be expressed in Equation (5).

$$
\begin{aligned}
H_{b}\left(Q, Q_{r}, x\right) & =h\left[\int_{t_{j}}^{t_{j}+Q_{r} / D} I(t) d t+\int_{t_{j}+x}^{t_{j+1}} I(t) d t\right] \\
& =h\left[\int_{t_{j}}^{t_{j}+Q_{r} / D}\left(Q_{r}-D\left(t-t_{j}\right)\right) d t+\int_{t_{j}+x}^{t_{j+1}}\left(Q+Q_{r}-D\left(t-t_{j}\right)\right) d t\right] \\
& =\frac{h}{2 D}\left[\left(Q_{r}+Q-D x\right)^{2}\right]
\end{aligned}
$$

Based on the discussions above, the expected holding cost per cycle, $E_{X}\left(H\left(Q, Q_{r}, X\right)\right)$, is calculated as:

$$
\begin{aligned}
E_{X}\left(H\left(Q, Q_{r}, X\right)\right)= & \frac{h}{2 D}\left[\int_{0}^{Q_{r} / D}\left(\left(Q_{r}+Q-D x\right)^{2}-\left(Q_{r}-D x\right)^{2}\right) f(x) d x+\int_{Q_{r} / D}^{\infty}\left(Q_{r}+Q-D x\right)^{2} f(x) d x\right] \\
= & \frac{h}{2 D}\left[\int_{0}^{Q_{r} / D}\left(Q_{r}+Q-D x\right)^{2} f(x) d x+\int_{Q_{r} / D}^{\infty}\left(Q_{r}+Q-D x\right)^{2} f(x) d x\right. \\
& \left.-\int_{0}^{Q_{r} / D}\left(Q_{r}-D x\right)^{2} f(x) d x\right] \\
= & \frac{h}{2 D}\left[\int_{0}^{\infty}\left(Q_{r}+Q-D x\right)^{2} f(x) d x-\int_{0}^{Q_{r} / D}\left(Q_{r}-D x\right)^{2} f(x) d x\right] \\
= & \frac{h}{2 D}\left[\int_{0}^{\infty}\left(Q^{2}+2 Q Q_{r}+Q_{r}^{2}-2 D Q x-2 D Q_{r} x+D^{2} x^{2}\right) f(x) d x\right. \\
& \left.\quad-\int_{0}^{Q_{r} / D}\left(Q_{r}^{2}-2 D Q_{r} x+D^{2} x^{2}\right) f(x) d x\right] \\
= & \frac{h}{2 D}\left[\left(Q^{2}+2 Q Q_{r}+Q_{r}^{2}\right) \int_{0}^{\infty} f(x) d x-2 D\left(Q+Q_{r}\right) \int_{0}^{\infty} x f(x) d x+D^{2} \int_{0}^{\infty} x^{2} f(x) d x\right. \\
& \left.-Q_{r}^{2} \int_{0}^{Q_{r} / D} f(x) d x-2 D Q_{r} \int_{0}^{Q_{r} / D} x f(x) d x-D^{2} \int_{0}^{Q_{r} / D} x^{2} f(x) d x\right] .
\end{aligned}
$$

We remark that Equation (6) is the expected holding cost per cycle, and we additionally need to take the residual part (i.e., inventory profiles over $\left(0, t_{1}\right)$ and $\left(t_{n}, H\right)$ in Figure 1$)$ into account to 
completely calculate the expected total holding costs completely. Then, the corresponding holding cost $H_{c}(Q)$ for the residual part can be simply represented by:

$$
H_{c}(Q)=h \int_{0}^{Q / D} I(t) d t=\frac{h Q^{2}}{2 D} .
$$

Finally, we can calculate the total expected holding $\operatorname{cost} \mathcal{H C}\left(Q, Q_{r}\right)$ by combining Equations (6) and (7) as below.

$$
\mathcal{H C}\left(Q, Q_{r}\right)=\left(\frac{D}{Q}-1\right) E_{X}\left(H\left(Q, Q_{r}, x\right)\right)+H_{c}(Q)
$$

So far, we have derived the expected holding cost over the planning horizon for the conventional EOQ model under lead-time uncertainty. As mentioned earlier, the concomitant model under study incorporates the aspects of sustainability, and we now discuss how such aspects may influence the expected holding cost. In practice, carrying additional inventory incurs some emission cost due to factors such as the emissions for space, from maintenance facilities and by scrapped materials. Furthermore, the emission costs for holding inventory and for scrapped materials are separated into the one of the previous studies (for example, [12]). However, they should have been included in a portion of the holding cost coefficient, as in Equation (9).

$$
h^{*}=\left(h+c_{b} \times b+\beta \times\left(\left(p-p_{s}\right)+a \times c_{a}\right)\right)
$$

For this reason, this paper will use $h^{*}$, the holding cost with emission per item per unit time, in place of $h$.

\subsection{Shortage Cost $\mathcal{S C}$}

Shortage cost is a sort of penalty cost due to the lack of product availability. According to Campo et al. [17], the stock-out cost depends on many factors, such as the availability of acceptable alternatives, deal proneness, item loyalty, private label buyers, product importance, the regular package size and other package sizes. However, since most of the factors are qualitative, it is difficult to measure them. Moreover, the ways to obtain stock-out costs can differ depending on the types of items or their sectors. Thus, it is conventional to use a fraction of the unit price as the shortage cost, as is done in this paper.

Shortage occurs in the same situation for which we derived Equation (5). In accordance with the discussion above, the shortage cost when the lead-time is $x$ is given in Equation (10) below:

$$
S C\left(Q, Q_{r}, x\right)=s \int_{t_{j}+Q_{r} / D}^{t_{j}+x}-I(t) d t=\frac{s\left(Q_{r}-D x\right)^{2}}{2 D}
$$

and hence, the expected shortage cost per cycle becomes:

$$
\begin{aligned}
E_{X}\left[S C\left(Q, Q_{r}, X\right)\right] & =\frac{s}{2 D} \int_{Q_{r} / D}^{\infty}\left(Q_{r}-D x\right)^{2} f(x) d x=\frac{s}{2 D} \int_{Q_{r} / D}^{\infty}\left(Q_{r}^{2}-2 D Q_{r} x+D^{2} x^{2}\right) f(x) d x \\
& =\frac{s}{2 D}\left[Q_{r}^{2} \int_{Q_{r} / D}^{\infty} f(x) d x-2 D Q_{r} \int_{Q_{r} / D}^{\infty} x f(x) d x+D^{2} \int_{Q_{r} / D}^{\infty} x^{2} f(x) d x\right] .
\end{aligned}
$$

Therefore, the annual shortage cost $\mathcal{S C}$ is $\mathcal{S C}\left(Q, Q_{r}\right)=\left(\frac{D}{Q}-1\right) E_{X}\left[S C\left(Q, Q_{r}, X\right)\right]$ as per the discussion on $\mathcal{H C}$.

\subsection{Transportation Cost $\mathcal{T} \mathcal{P C}$}

The transportation costs, in general, consist of two components: fixed and variable costs. Fixed costs include truck leasing cost, driver salaries, and so on, which are generally independent 
of order quantity. However, we assume that they depend on the travel distance. On the other hand, variable costs are additional costs that are proportional to the order quantity.

In this model, we consider multi-modal transportation options, and the travel distance depends on which shipment mode is used. When it comes to the transportation cost formulation, we take the multi-modal transportation options into account as presented in Equation (12), which is similar to the transportation function given in Battini et al. [12].

$$
\mathcal{T P C}\left(Q, Q_{r}\right)=\left[\sum_{k \in \mathcal{K}}\left(\left(c_{\text {int }-f i x, k}+c_{\text {ext-fix, }, k}\right) \times d_{k}+\left(c_{\text {int-var }, k}+c_{\text {ext-var }, k}\right) \times d_{k} \times Q\right)\right] \times \frac{D_{Y}}{Q}
$$

As shown in Equation (12), both internal costs (e.g., vehicle rents, driver salaries, insurance and fuel fees) and external costs (e.g., air pollution from fuel, road congestion, traffic accidents and land use impacts) are considered as fixed, as well as variable transportation costs [4]. We note that the transportation distance depends on the transportation mode used.

\subsection{Total Annual Cost $\mathcal{T C}$}

So far, we have examined each cost component of the concomitant model under interest. We now present the mathematical formulation for the sustainable EOQ under lead-time uncertainty and multi-modal transportation options as follows.

$$
\begin{aligned}
& \mathcal{T}\left(Q, Q_{r}\right) \\
= & \mathcal{O C}(Q)+\mathcal{H C}\left(Q, Q_{r}\right)+\mathcal{S C}\left(Q, Q_{r}\right)+\mathcal{T} \mathcal{P C}\left(Q, Q_{r}\right) \\
= & \left(\frac{D_{Y}}{Q}\right) \times o \\
& +\left(\frac{D_{Y}}{Q}-1\right) \frac{h^{*}}{2 D}\left[\int_{0}^{Q_{r} / D}\left(\left(Q_{r}+Q-D x\right)^{2}-\left(Q_{r}-D x\right)^{2}\right) f(x) d x\right. \\
& \left.+\int_{Q_{r} / D}^{\infty}\left(\left(Q_{r}+Q-D x\right)^{2}\right) f(x) d x\right] \\
& +\frac{h^{*} Q^{2}}{2 D}+\left(\frac{D_{Y}}{Q}-1\right) \frac{s}{2 D}\left[\int_{Q_{r} / D}^{\infty}\left(Q_{r}-D x\right)^{2} f(x) d x\right] \\
& +\left(\frac{D_{Y}}{Q}\right) \times\left[\sum_{k}\left(\left(c_{i n t-f i x, k}+c_{e x t-f i x, k}\right) \times d_{k}+\left(c_{i n t-v a r, k}+c_{\text {ext }-v a r, k}\right) \times d_{k} \times Q\right)\right] \\
= & \left(\frac{D_{Y}}{Q}\right) \times o \\
& +\left(\frac{D_{Y}}{Q}-1\right) \frac{h^{*}}{2 D}\left[\left(Q^{2}+2 Q Q_{r}\right) \int_{0}^{Q_{r} / D} f(x) d x-2 Q D \int_{0}^{Q_{r} / D} x f(x) d x\right. \\
& \left.+\left(Q^{2}+2 Q Q_{r}+Q_{r}^{2}\right) \int_{Q_{r} / D}^{\infty} f(x) d x-2 D\left(Q+Q_{r}\right) \int_{Q_{r} / D}^{\infty} x f(x) d x+D^{2} \int_{Q_{r} / D}^{\infty} x^{2} f(x) d x\right] \\
& +\frac{h^{*} Q^{2}}{2 D}+\left(\frac{D_{Y}}{Q}-1\right) \frac{s}{2 D}\left[Q_{r}^{2} \int_{Q_{r} / D}^{\infty} f(x) d x-2 D Q_{r} \int_{Q_{r} / D}^{\infty} x f(x) d x+D^{2} \int_{Q_{r} / D}^{\infty} x^{2} f(x) d x\right] \\
& +\left(\frac{D_{Y}}{Q}\right) \times\left[\sum_{k}\left(\left(c_{i n t-f i x, k}+c_{e x t-f i x, k}\right) \times d_{k}+\left(c_{i n t-v a r, k}+c_{\text {ext }-v a r, k}\right) \times d_{k} \times Q\right)\right]
\end{aligned}
$$

We now examine the functional property of $\mathcal{T C}$ for determining the optimal order quantity $Q^{*}$ and reorder point $Q_{r}^{*}$. By evaluating the Hessian matrix of $\mathcal{T C}$ with respect to $Q$ and $Q_{r}$, it is straightforward to show that the Hessian matrix is positive semi-definite, and hence, we simply omit the proof. Based on the results, we can derive the following proposition.

Proposition 1. The total annual cost function $\mathcal{T C}\left(Q, Q_{r}\right)$ is jointly convex in $Q$ and $Q_{r}$. 
We note that, according to Proposition $1, Q^{*}$ and $Q_{r}^{*}$ simultaneously satisfy the system of linear equations $\frac{\partial \mathcal{T C}\left(Q, Q_{r}\right)}{\partial Q}=0$ and $\frac{\partial \mathcal{T C}\left(Q, Q_{r}\right)}{\partial Q_{r}}=0$.

\section{Numerical Experiments and Sensitivity Analysis}

In this section, we perform numerical experiments based on the benchmark instance whose data (refer to Table 1) are derived from the literature, particularly [12], and examine several scenarios using a sensitivity analysis in order to make interesting and insightful observations.

Table 1. Input data (extracted from [12]).

\begin{tabular}{llll}
\hline Parameter & Value & Parameter & Value \\
\hline$D$ & 40,000 (units/year) & $O$ & $400(\$ /$ order $)$ \\
$p$ & $10(\$ /$ unit $)$ & $p_{s}$ & $5(\$ /$ unit $)$ \\
$h$ & $2.5(\$ /$ unit $)$ & $s$ & $5(\$ /$ unit $)$ \\
$a$ & 0.002 (tons/unit) & $b$ & $0.017\left(\mathrm{~m}^{3} /\right.$ unit $)$ \\
$c_{a}$ & $13(\$ /$ ton $)$ & $c_{b}$ & $0.55\left(\$ / \mathrm{m}^{3}\right)$ \\
$\beta$ & $10(\%)$ & $c v$ & 0.2 \\
$c_{\text {int-fix,truck }}$ & $0.8(\$ / \mathrm{km})$ & $c_{\text {ext-fix,truck }}$ & $0.2(\$ / \mathrm{km})$ \\
$c_{\text {int-var,truck }}$ & $0.01 \times 0.017\left(\$ / \mathrm{m}^{3} \mathrm{~km}\right)$ & $c_{\text {ext-var,truck }}$ & $0.02 \times 0.017\left(\$ / \mathrm{m}^{3} \mathrm{~km}\right)$ \\
$c_{\text {int-fix,rail }}$ & $0.6(\$ / \mathrm{km})$ & $c_{\text {ext-fix,rail }}$ & $0.0066(\$ / \mathrm{km})$ \\
$c_{\text {int-var,rail }}$ & $0.007 \times 0.017\left(\$ / \mathrm{m}^{3} \mathrm{~km}\right)$ & $c_{\text {ext-var,rail }}$ & $0\left(\$ / \mathrm{m}^{3} \mathrm{~km}\right)$ \\
$c_{\text {int-fix,ship }}$ & $0.048(\$ / \mathrm{km})$ & $c_{\text {ext-fix, ship }}$ & $0.0044(\$ / \mathrm{km})$ \\
$c_{\text {int-var,ship }}$ & $0.003 \times 0.017\left(\$ / \mathrm{m}^{3} \mathrm{~km}\right)$ & $c_{\text {ext-var,ship }}$ & $0\left(\$ / \mathrm{m}^{3} \mathrm{~km}\right)$ \\
\hline
\end{tabular}

In the following subsections, we first perform the sensitivity analysis in which we vary one of the key parameters of interest while keeping all the others constant. We especially vary the parameters of stock-out cost and external cost. Furthermore, we take a look at an example including multi-modal transportation options with lead-time uncertainty and see how the consideration of sustainability can change the sourcing decisions.

\subsection{Effects of Stock-Out Cost}

We first analyze the impact of changes in stock-out cost on the decisions of an S-EOQ model. As mentioned in Section 3, defining the shortage cost is one of the difficult tasks. If the model of interest is heavily influenced by the stock-out cost, it would be hardly used in practice. Thus, a sensitivity analysis varying stock-out cost is performed. For this purpose, we test various scenarios, such as different distances, different mono-modals, different modal combinations and different coefficients of variation for lead-time $X$. Since we observe similar results from the experiments with most scenarios, we present only parts of the results in the Appendix A for reference.

From the various scenarios we examine in Tables A1-A9 in the Appendix A, we observe how the optimal order quantity $\left(Q^{*}\right)$, reorder inventory level $\left(Q_{r}^{*}\right)$ and total annual cost change with respect to changes in stock-out cost from $100 \%$ to $500 \%$ in increments of $50 \%$. For example, Tables A1-A3 present the sensitivity results from scenarios with various shipment distances and modals. When increasing the stock-out cost by $500 \%$, the order quantity $Q^{*}$ only slightly increases by $0.45 \%$ at most, while the reorder point $Q_{r}^{*}$ increases by about $9 \%$. When adjusting the optimal order quantity, as well as the reorder point accordingly in the mathematical model, the total annual cost only slightly increases by $0.8 \%$ at most, implying that in the S-EOQ model used, the impact of changes in the stock-out cost on total annual costs would be minimal. The other results are similar to those previously discussed: $Q^{*}, Q_{r}^{*}$ and total costs could increase no more than $3.63 \%, 10.85 \%$ and $2.65 \%$ when the stock-out cost increases by up to $500 \%$. 


\subsection{Effects of Lead-Time Variability}

We next perform a sensitivity analysis for changes in lead-time variability. Specifically, we vary the coefficient of variation (CV) of the lead-time $X$ and see how the total $\operatorname{cost} \mathcal{T C}$, order quantity $Q$ and re-order point $Q_{r}$ change. As in Section 4.1, similar results were observed in numerous experiments, so we provide below on representative example result from an international sourcing case, which we will examine further in Section 4.4. When changing the coefficient of variation from 0.1 to 0.9 , the following results are observed.

As presented in Figure 2, we obtain the intuitive result that the optimal total cost, order quantity and re-order point increase as the $\mathrm{CV}$ representing lead-time variability increases. The total cost only increases by $9.09 \%$ (from $\$ 53,693.57$ to $\$ 58,573.15$ ) when changing the $C V$ from 0.1 to 0.9 , while the order quantity and re-order point increase by $22.93 \%$ (from 6494.13 to 7982.93 ) and $156.06 \%$ (from 1462.79 to 3745.47 ), respectively. Interestingly, the re-order point increases more rapidly than the order quantity as the CV increases. The observations indicate that as lead-time variability increases, the optimal order quantity and, especially, reorder point adjust accordingly and that such adjustments reduce the increase of the rate of the total cost. Thus, in terms of total cost, the S-EOQ model could be only weakly sensitive to changes in $\mathrm{CV}$.

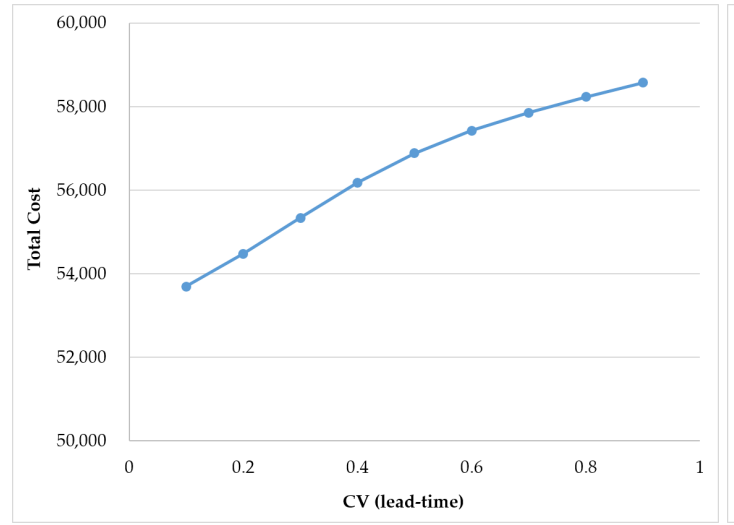

(a) Changes in total cost $\mathcal{T C}$

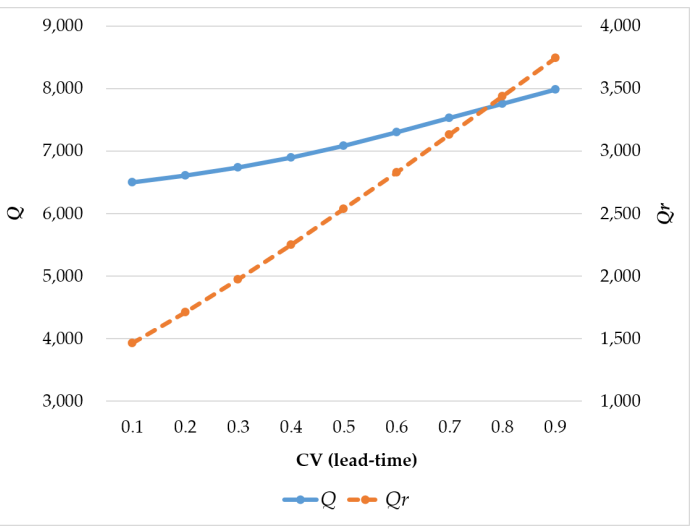

(b) Changes in $Q$ and $Q_{r}$

Figure 2. Effects of lead-time variability on (a) $\mathcal{T C}$ and (b) $Q$ and $Q_{r}$.

\subsection{Effects of External Costs}

We now examine how the consideration of external transportation costs (or sustainability) in an EOQ model influences the choice of transportation mode(s). Let us consider the different purchasing possibilities for a product similar to that in the case study in Battini et al. [12]. They examine the real-world case of a buyer company located in northeastern Italy close to intermodal terminals and compare two scenarios depending on transportation mode choice, particularly road-only vs. a road-rail combination, given that the company purchases the product from the same supplier. In this paper, we additionally examine other scenarios of transportation mode combinations, including combined truck/rail/ship transport, which is commonly used at the international level. To better understand the differences, assume the unit purchasing price is constant across all of the examined cases. We note that unlike [12], our model considers the uncertainty of the lead-time, and we set the coefficient of variance of the lead-time to 0.2 in this experiment. Table 2 summarizes the total annual costs of EOQ (a model without taking sustainability into account) and then of S-EOQ (a model with taking sustainability into account) to see the effects on the EOQ model of sustainability considerations combined with different choices of transportation modes. 
Table 2. Comparison between EOQ (without sustainability) and S-EOQ (with sustainability) under lead-time uncertainty.

\begin{tabular}{clccccc}
\hline \multicolumn{2}{c}{ Cases } & Truck & Rail & Ship & $\mathcal{T C}($ EOQ) & $\mathcal{T C}($ S-EOQ $)$ \\
\hline Mono-modal & Case 1 (T) & $1200 \mathrm{~km}$ & - & - & $\$ 26,293$ & $\$ 44,180$ \\
\hline & Case 2 (T-R) & $600 \mathrm{~km}$ & $600 \mathrm{~km}$ & - & $\$ 24,310$ & $\$ 33,346$ \\
& Case 3 (T-R-S) & $600 \mathrm{~km}$ & $300 \mathrm{~km}$ & $300 \mathrm{~km}$ & $\$ 22,310$ & $\$ 31,390$ \\
& Case 4 (T-S) & $600 \mathrm{~km}$ & - & $600 \mathrm{~km}$ & $\$ 20,198$ & $\$ 29,353$ \\
\cline { 2 - 7 } Multi-modal & Case 5 (T-R) & $300 \mathrm{~km}$ & $900 \mathrm{~km}$ & - & $\$ 23,305$ & $\$ 27,883$ \\
& Case 6 (T-R-S) & $300 \mathrm{~km}$ & $600 \mathrm{~km}$ & $300 \mathrm{~km}$ & $\$ 21,266$ & $\$ 25,871$ \\
& Case 7 (T-R-S) & $300 \mathrm{~km}$ & $300 \mathrm{~km}$ & $600 \mathrm{~km}$ & $\$ 19,122$ & $\$ 23,764$ \\
& Case 8 (T-S) & $300 \mathrm{~km}$ & - & $900 \mathrm{~km}$ & $\$ 16,841$ & $\$ 21,533$ \\
\hline
\end{tabular}

Assuming that Case 1 uses a truck only and Cases 2-8 use more than one mode of transport when the company purchases goods from the same supplier, for example, the total annual costs without external costs are $\$ 26,293$ for Case 1 and $\$ 24,310$ for Case 2, and the total annual costs with external costs are $\$ 44,180$ and $\$ 33,346$, respectively. Similarly, for the cases in which the percentage of truck use is half of the total shipping distance $1200 \mathrm{~km}$ (i.e., Cases 2-4), the total annual costs without external costs are $\$ 22,310$ for Case 3 and $\$ 20,198$ for Case 4, and the total annual costs with external costs are $\$ 31,390$ and $\$ 29,353$, respectively. The total annual costs for Cases 5-8 are also presented in Table 2 . We note that the total annual costs do not differ widely between Cases 1 and 2 when using EOQ, but that this is not the case when using S-EOQ. However, the total annual costs do not differ widely among the multi-modal cases (Cases 2-8) when using either EOQ or S-EOQ, although the difference could be relatively large for the cases with a high percentage of truck use (see Figure 3a). We can also observe that when the shipment relies on more sustainable transportation modes in the decision model, the marginal increase in total annual costs from EOQ to S-EOQ becomes insignificant. Those results are intuitive because the S-EOQ model is indeed concerned with the choice of sustainable transportation options, while the conventional EOQ is not, and thus, the difference between the total annual costs of EOQ and S-EOQ is less significant when more sustainable transport modes are used.

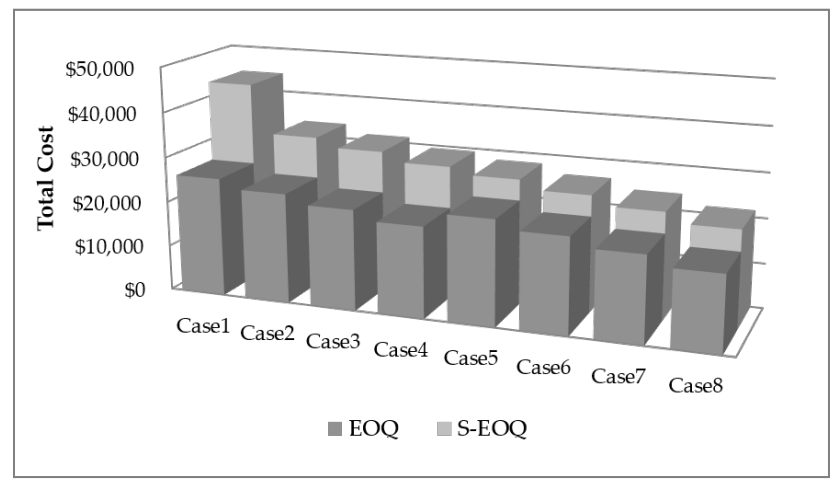

(a)

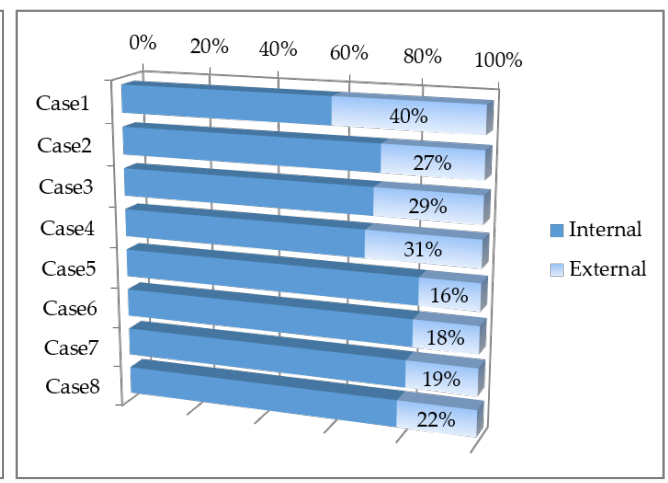

(b)

Figure 3. Differences in total cost between EOQ and S-EOQ (a) and the proportions of internal and external costs in S-EOQ (b) for Cases 1-8.

In addition, we also evaluate the proportion of internal and external transportation costs in an S-EOQ model for all of the cases. As shown in Figure 3b, the external costs account for $40 \%$ in the mono-modal case and less than about $30 \%$ in multi-modal cases. This result shows that multi-modal cases are indeed more environmentally friendly, a result that is similar to the findings in [12].

We now further take a look at an example of how the consideration of sustainability (especially, externality costs) in the model can influence the choice among two different shipping routes connecting 
the same source and destination. Let us assume that a company is doing some business from Shanghai in China to Oklahoma City in the U.S. The company has two options when shipping a product: one shipping route is via Long Beach port and the other via Houston port, as presented in Figure 4.

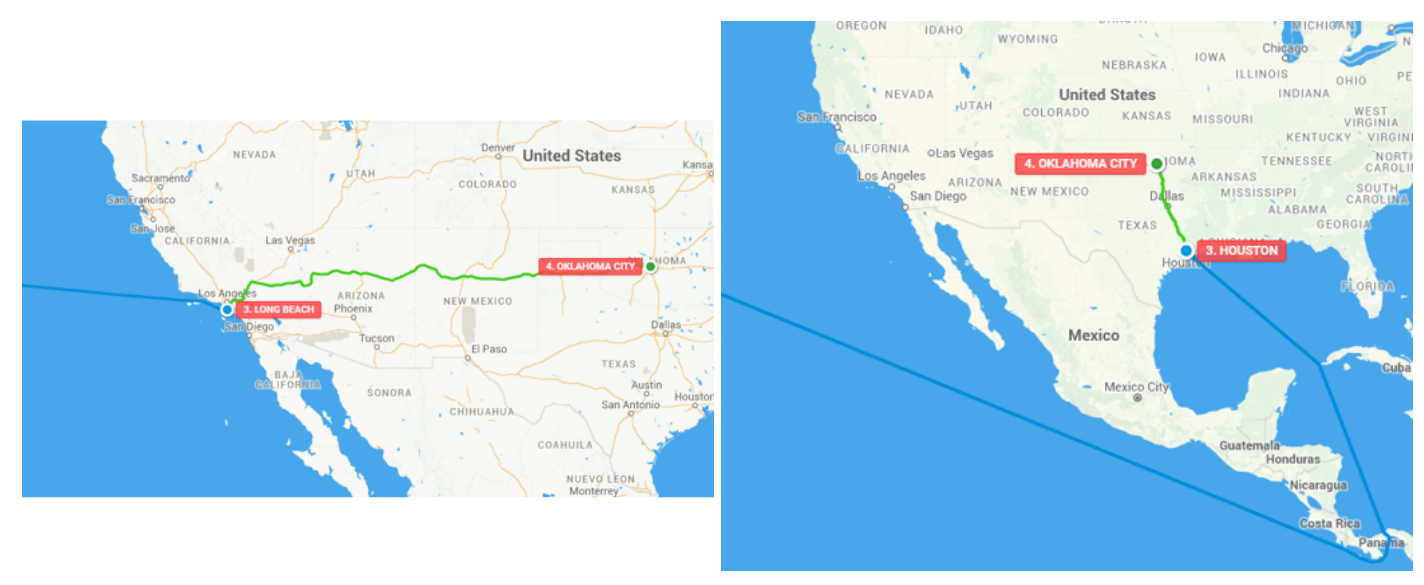

(a) Long beach route

(b) Houston route

Figure 4. Two routes from Shanghai to Oklahoma City via the Long Beach port (a) and Houston port (b).

The distances of the two shipping routes between Shanghai and Oklahoma City are presented in Table 3. As shown in Figure 4, the total distance of the route via the Houston port is about $51.1 \%$ longer than the route via the Long Beach port. Based on the distance information along with the data in Table 1, we calculate the total annual costs with and without sustainability considerations. When it comes to the total annual cost without adopting sustainability considerations, the costs of the Long beach and Houston routes are $\$ 63,003.35$ and $\$ 66,799.56$, respectively, and thus, the Long beach route is the more economical choice given the criterion used. However, if we incorporate the aspects of emissions during shipment in the model, the results suggest the Houston route should be selected. Specifically, as presented in Figure 5, the total costs of the Long beach and Houston routes are changed to $\$ 94,928.25$ and $\$ 78,288.58$ respectively.

Table 3. Distances of two routes connecting between Shanghai and Oklahoma City.

\begin{tabular}{cccc}
\hline Route Via & Truck & Ship & Total \\
\hline Long beach port & $2185.02 \mathrm{~km}$ & $10,597.44 \mathrm{~km}$ & $12,782.46 \mathrm{~km}$ \\
Houston port & $752.13 \mathrm{~km}$ & $18,560.99 \mathrm{~km}$ & $19,313.12 \mathrm{~km}$ \\
\hline
\end{tabular}

This numerical example shows that the incorporation of sustainability considerations into the EOQ model could change the replenishment strategies, as well as the transportation modality. The S-EOQ model suggests the adoption of intermodal transportation rather than mono-modal road transportation where possible and the use of more sustainable transportation modes in multi-modal transportation with less impact on purchasing strategies, compared to the traditional EOQ model. We remark that the traditional EOQ model cannot easily capture the practical difference between mono-modal and multi-modal transportation options (i.e., the conventional model treats them indifferently) and moreover fails to understand the benefits of adopting more sustainable purchasing options. 


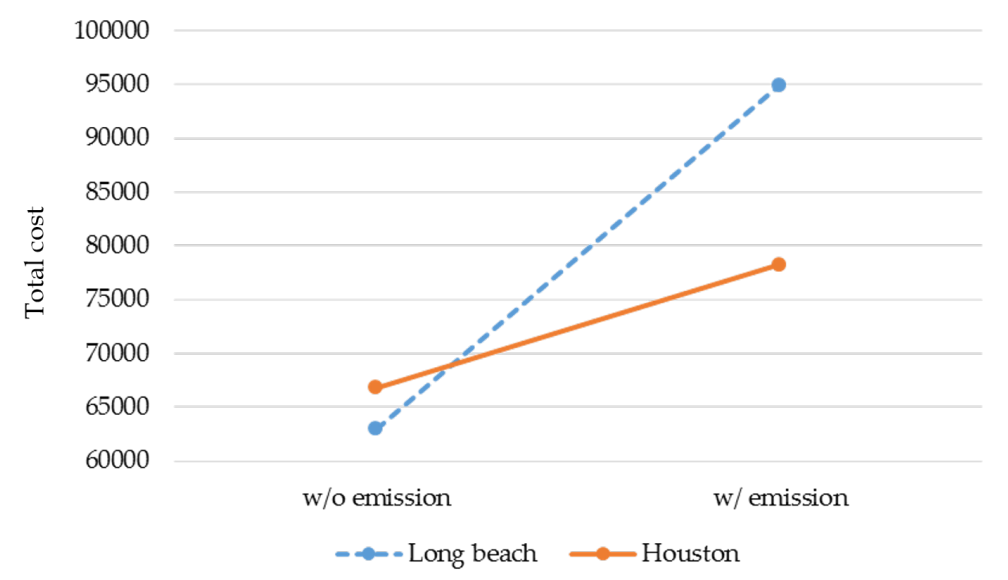

Figure 5. Comparison of the total annual costs between two routes depending on sustainability considerations.

\subsection{Effects of Domestic vs. International Sourcing}

In this section, we examine the effects on sourcing strategies of whether the traditional EOQ model incorporates the sustainability considerations. We see how varying the unit price can influence the total annual costs and preferences for international or domestic sourcing. Let us assume that there is a company that has the option of either the international sourcing from Shanghai or domestic sourcing from Phoenix, as shown in Figure 6.

Based on the distance information in Table 4, we first examine how the inclusion of sustainability considerations into the traditional EOQ model and the changes in external emission costs in the S-EOQ model affect the sourcing decision. As presented in Figure 7, the EOQ model (without sustainability considerations) favors the domestic sourcing. However, in this numerical experiment, as we increase the external emission costs in the S-EOQ model 1.5-times and two-times, we observe that the sourcing decision changes from domestic sourcing to international sourcing.

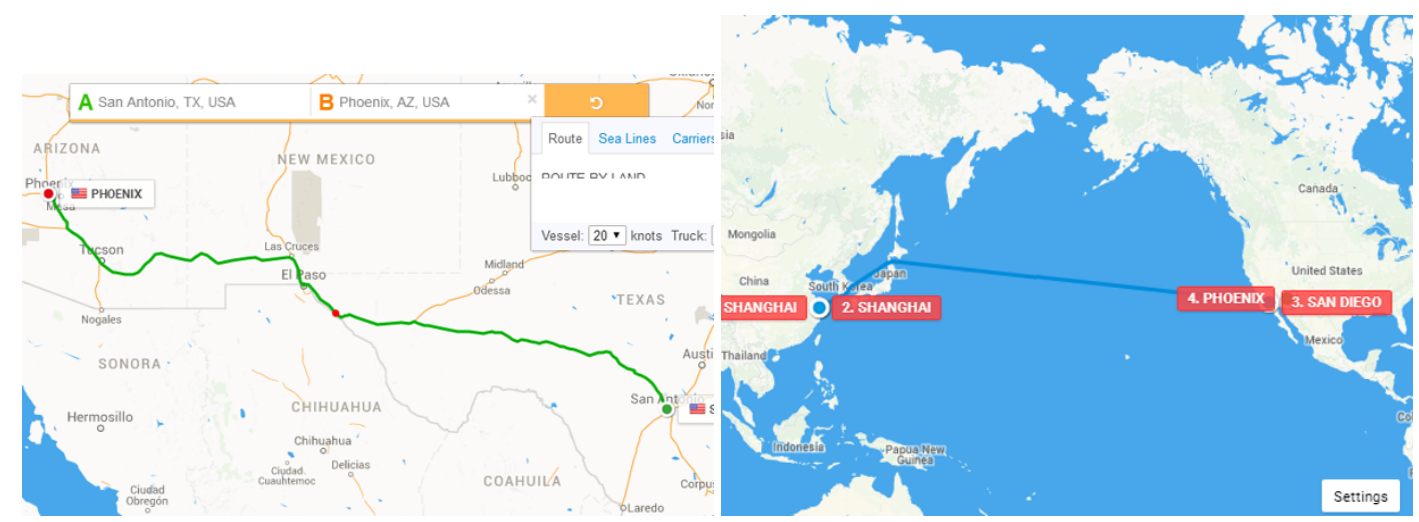

(a) Domestic sourcing route

(b) International sourcing route

Figure 6. Example of (a) domestic vs. (b) international sourcing options.

Table 4. Distances of the domestic and international sourcing routes.

\begin{tabular}{cccc}
\hline Sourcing & Truck & Ship & Total \\
\hline Domestic & $1600.00 \mathrm{~km}$ & $0 \mathrm{~km}$ & $1600.00 \mathrm{~km}$ \\
International & $582.79 \mathrm{~km}$ & $10,746.77 \mathrm{~km}$ & $11,329.56 \mathrm{~km}$ \\
\hline
\end{tabular}




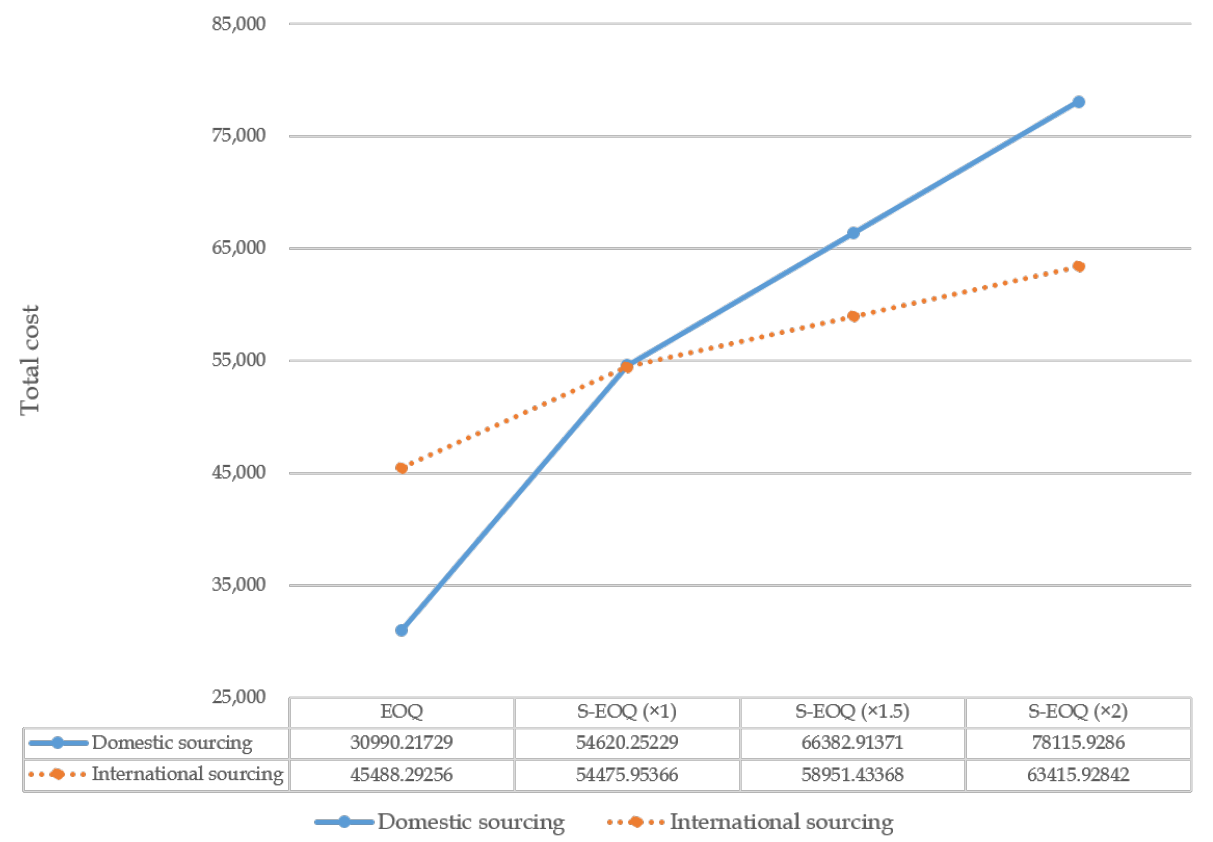

Figure 7. Effects of changes in external emission costs on $\mathcal{T C}$.

We also vary the unit price $p$ with each (S-)EOQ model, and Figure 8 presents how the total annual costs of the two sourcing options change as a result. As the external emission costs increase, the same pattern of sourcing decision changes are observed in Figure 7. From Figure 8a, the traditional EOQ model suggests the domestic sourcing strategy, and the difference in total annual costs between the two sourcing strategies increases as $p$ increases. However, the numerical results in Figure $8 \mathrm{~b}$ show that in an EOQ model incorporating environmental factors, intuitively, the preferred sourcing decision changes from international sourcing to domestic sourcing. Furthermore, as the consideration of external emission costs becomes more stressed (Figure 8c or Figure 8d) in the replenishment decisions, the sustainable EOQ model favors more the international sourcing strategy, which includes more sustainable transportation modes. We further observe from the numerical results that the difference in total annual costs between the two sourcing strategies decreases as $p$ increases when the external emission costs are increased either 1.5-times or two-times. This implies that for highly sustainable EOQ models, the benefits from international sourcing decrease as the unit price increases.

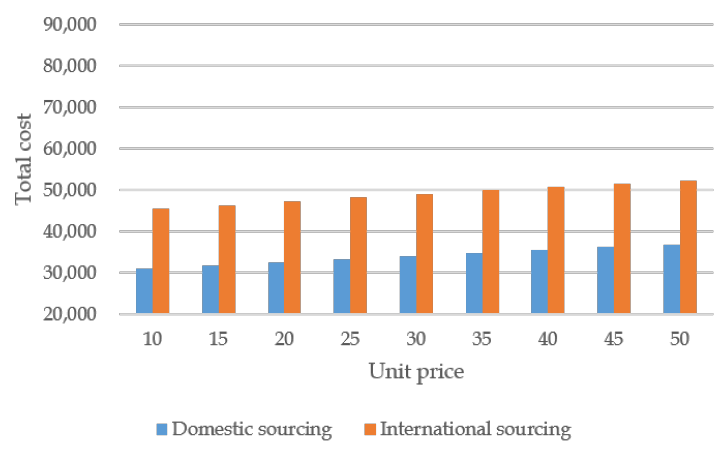

(a)

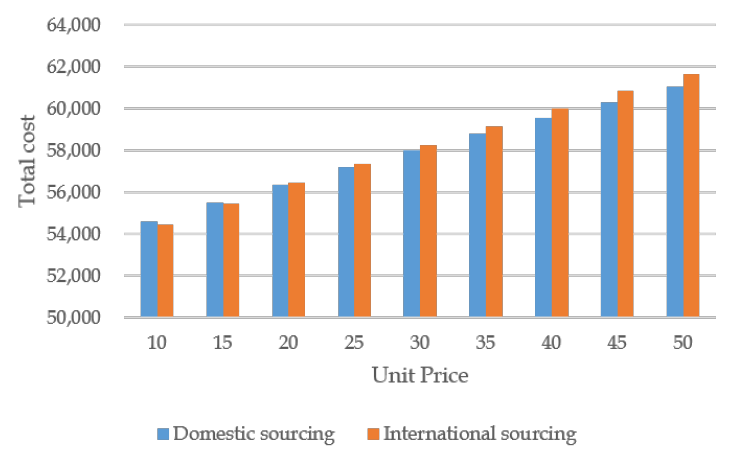

(b)

Figure 8. Cont. 


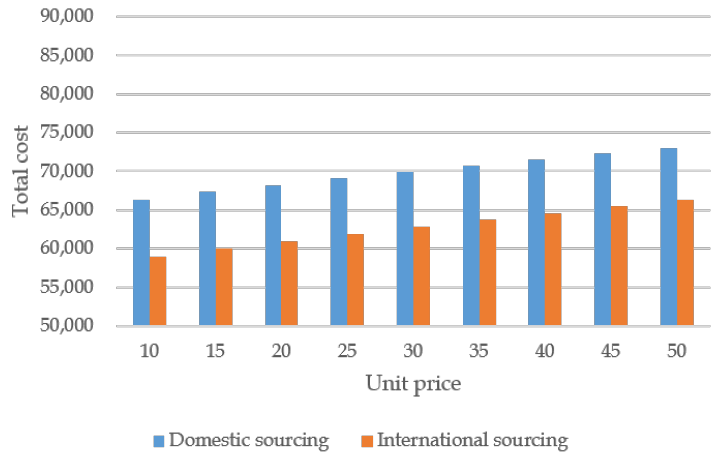

(c)

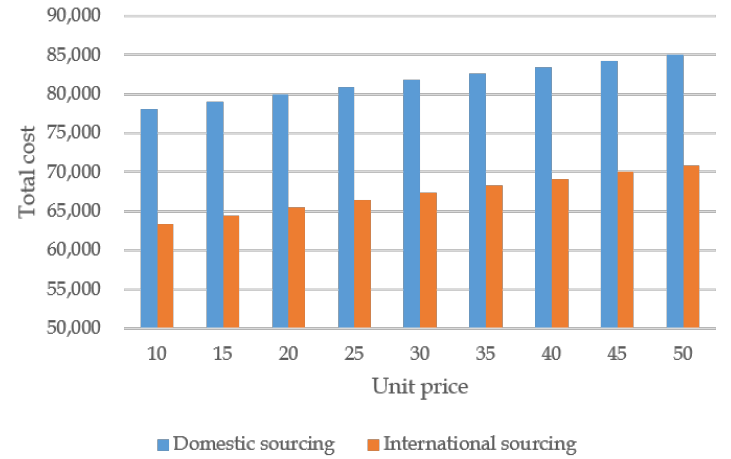

(d)

Figure 8. Effects of changes in $p$ on $\mathcal{T C}$ and sourcing decision. (a) EOQ; (b) S-EOQ (×1); (c) S-EOQ $(\times 1.5)$; (d) S-EOQ $(\times 2)$.

\section{Conclusions}

In this paper, we examined a sustainable EOQ model under stochastic lead-time and multi-modal transportation options. Specifically, we derived a detailed mathematical model of the sustainable EOQ model and performed numerical experiments to examine the effects of sustainability considerations on operational decisions. We first showed that the sustainable EOQ model is insensitive to stock-out costs under lead-time uncertainty. The numerical experiments showed that the EOQ model with the inclusion of environment and sustainability factors would potentially suggest changes in the transportation modality toward the inclusion of more sustainable transportation modes and changes in sourcing strategies and replenishment policies. Therefore, our results highlight the importance of sustainability considerations in the operational decisions including inventory management decisions and transportation modal combination selections for international trade, given that there are growing concerns about the environmental and sustainability issues of global trading.

Extending the model to consider transition processing times due to customs, waiting at a border crossings and terminal handling activities would be an interesting focus for future research. We remark that each border-crossing in international trade generally requires more than 15 steps and that its processing time varies from one country to another and is usually unpredictable [18]. Furthermore, since some countries have longer processing time than actual transportation times, the border processing time could strongly contribute to lead-time uncertainty in international trade replenishment decisions.

Acknowledgments: We would like to thank the two anonymous reviewers for their valuable comments. This work was supported by a Korea University grant (K1427391) and partly by a grant (Q1620591) from Dong Yang Piston.

Author Contributions: All of the authors contributed significantly to the completion of this manuscript. Soon-Kyo Lee developed the model and performed the experiments. Seung Ho Yoo contributed to designing the theoretical verifications and was involved in the results discussion. Taesu Cheong developed the overall idea, as well as the basic outline of the paper and prepared the manuscript. All authors read and approved the final manuscript.

Conflicts of Interest: The authors declare no conflict of interest. 


\section{Appendix A}

Table A1. Effects of the changes in $s$ depending on different distances by truck.

\begin{tabular}{|c|c|c|c|}
\hline & \multicolumn{3}{|c|}{$1000 \mathrm{~km}$} \\
\hline Stock-Out & $Q$ & $Q_{r}$ & Total Cost (\$) \\
\hline $100 \%$ & $6104.37(100.00 \%)$ & $68.62(100.00 \%)$ & $38,820.26(100.00 \%)$ \\
\hline $150 \%$ & $6104.45(100.00 \%)$ & $70.32(102.47 \%)$ & $38,824.16(100.01 \%)$ \\
\hline $200 \%$ & $6104.49(100.00 \%)$ & $71.47(104.14 \%)$ & $38,826.83(100.02 \%)$ \\
\hline $250 \%$ & $6104.56(100.00 \%)$ & $72.33(105.41 \%)$ & $38,828.85(100.02 \%)$ \\
\hline $300 \%$ & $6104.63(100.00 \%)$ & $73.02(106.41 \%)$ & $38,830.46(100.03 \%)$ \\
\hline $350 \%$ & $6104.65(100.00 \%)$ & $73.60(107.25 \%)$ & $38,831.80(100.03 \%)$ \\
\hline $400 \%$ & $6104.68(100.01 \%)$ & $74.09(107.96 \%)$ & $38,832.95(100.03 \%)$ \\
\hline $450 \%$ & $6104.71(100.01 \%)$ & $74.51(108.58 \%)$ & $38,833.96(100.04 \%)$ \\
\hline \multirow[t]{2}{*}{$500 \%$} & $6104.73(100.01 \%)$ & $74.89(109.13 \%)$ & $38,834.84(100.04 \%)$ \\
\hline & \multicolumn{3}{|c|}{$5000 \mathrm{~km}$} \\
\hline Stock-Out & $Q$ & $Q_{r}$ & Total Cost (\$) \\
\hline $100 \%$ & $12,025.67(100.00 \%)$ & $361.86(100.00 \%)$ & $138,329.32(100.00 \%)$ \\
\hline $150 \%$ & $12,027.36(100.01 \%)$ & $369.43(102.09 \%)$ & $138,344.05(100.01 \%)$ \\
\hline $200 \%$ & $12,028.56(100.02 \%)$ & $374.61(103.52 \%)$ & $138,354.19(100.02 \%)$ \\
\hline $250 \%$ & $12,029.48(100.03 \%)$ & $378.53(104.61 \%)$ & $138,361.87(100.02 \%)$ \\
\hline $300 \%$ & $12,030.21(100.04 \%)$ & $381.67(105.48 \%)$ & $138,368.05(100.03 \%)$ \\
\hline $350 \%$ & $12,030.83(100.04 \%)$ & $384.28(106.20 \%)$ & $138,373.20(100.03 \%)$ \\
\hline $400 \%$ & $12,031.36(100.05 \%)$ & $386.51(106.81 \%)$ & $138,377.61(100.03 \%)$ \\
\hline $450 \%$ & $12,031.84(100.05 \%)$ & $388.46(107.35 \%)$ & $138,381.46(100.04 \%)$ \\
\hline \multirow[t]{2}{*}{$500 \%$} & $12,032.25(100.05 \%)$ & $390.19(107.83 \%)$ & $138,384.88(100.04 \%)$ \\
\hline & \multicolumn{3}{|c|}{$10,000 \mathrm{~km}$} \\
\hline Stock-Out & $Q$ & $Q_{r}$ & Total Cost (\$) \\
\hline $100 \%$ & $16,749.41(100.00 \%)$ & $737.12(100.00 \%)$ & $254,511.59(100.00 \%)$ \\
\hline $150 \%$ & $16,754.60(100.03 \%)$ & $751.69(101.98 \%)$ & $254,535.40(100.01 \%)$ \\
\hline $200 \%$ & $16,758.22(100.05 \%)$ & $761.69(103.33 \%)$ & $254,551.80(100.02 \%)$ \\
\hline $250 \%$ & $16,760.97(100.07 \%)$ & $769.25(104.36 \%)$ & $254,564.26(100.02 \%)$ \\
\hline $300 \%$ & $16,763.20(100.08 \%)$ & $775.32(105.18 \%)$ & $254,574.28(100.02 \%)$ \\
\hline $350 \%$ & $16,765.06(100.09 \%)$ & $780.38(105.87 \%)$ & $254,582.65(100.03 \%)$ \\
\hline $400 \%$ & $16,766.67(100.10 \%)$ & $784.71(106.46 \%)$ & $254,589.81(100.03 \%)$ \\
\hline $450 \%$ & $16,768.08(100.11 \%)$ & $788.48(106.97 \%)$ & $254,596.08(100.03 \%)$ \\
\hline $500 \%$ & $16,769.32(100.12 \%)$ & $791.83(107.42 \%)$ & $254,601.64(100.04 \%)$ \\
\hline
\end{tabular}

Table A2. Effects of the changes in s depending on different distances by rail.

\begin{tabular}{cccc}
\hline & \multicolumn{3}{c}{$\mathbf{1 0 0 0} \mathbf{k m}$} \\
\hline Stock-Out & $Q$ & $Q_{r}$ & Total Cost (\$) \\
\hline $100 \%$ & $5185.58(100.00 \%)$ & $170.43(100.00 \%)$ & $20,486.03(100.00 \%)$ \\
$150 \%$ & $5185.78(100.00 \%)$ & $173.95(102.07 \%)$ & $20,494.57(100.04 \%)$ \\
$200 \%$ & $5185.92(100.01 \%)$ & $176.36(103.48 \%)$ & $20,500.45(100.07 \%)$ \\
$250 \%$ & $5186.01(100.01 \%)$ & $178.18(104.55 \%)$ & $20,504.91(100.09 \%)$ \\
$300 \%$ & $5186.12(100.01 \%)$ & $179.65(105.41 \%)$ & $20,508.49(100.11 \%)$ \\
$350 \%$ & $5186.20(100.01 \%)$ & $180.86(106.12 \%)$ & $20,511.48(100.12 \%)$ \\
$400 \%$ & $5186.30(100.01 \%)$ & $181.90(106.73 \%)$ & $20,514.04(100.14 \%)$ \\
$450 \%$ & $5186.35(100.01 \%)$ & $182.81(107.26 \%)$ & $20,516.28(100.15 \%)$ \\
$500 \%$ & $5186.39(100.02 \%)$ & $183.61(107.73 \%)$ & $20,518.26(100.16 \%)$ \\
\hline
\end{tabular}


Table A2. Cont.

\begin{tabular}{cccc}
\hline & \multicolumn{3}{c}{$\mathbf{5 0 0 0} \mathbf{~ k m}$} \\
\hline Stock-Out & $Q$ & $Q_{r}$ & Total Cost (\$) \\
\hline $100 \%$ & $9662.72(100.00 \%)$ & $893.04(100.00 \%)$ & $53,321.34(100.00 \%)$ \\
$150 \%$ & $9665.96(100.03 \%)$ & $908.99(101.79 \%)$ & $53,356.27(100.07 \%)$ \\
$200 \%$ & $9668.24(100.06 \%)$ & $919.97(103.02 \%)$ & $53,380.42(100.11 \%)$ \\
$250 \%$ & $9670.00(100.08 \%)$ & $928.30(103.95 \%)$ & $53,398.81(100.15 \%)$ \\
$300 \%$ & $9671.44(100.09 \%)$ & $935.00(104.70 \%)$ & $53,413.63(100.17 \%)$ \\
$350 \%$ & $9672.64(100.10 \%)$ & $940.59(105.32 \%)$ & $53,426.02(100.20 \%)$ \\
$400 \%$ & $9673.67(100.11 \%)$ & $945.38(105.86 \%)$ & $53,436.65(100.22 \%)$ \\
$450 \%$ & $9674.60(100.12 \%)$ & $949.56(106.33 \%)$ & $53,445.95(100.23 \%)$ \\
$500 \%$ & $9675.41(100.13 \%)$ & $953.27(106.74 \%)$ & $53,454.21(100.25 \%)$ \\
\hline & & $10,000 \mathbf{k m}$ & \\
\hline Stock-Out & $Q$ & $Q_{r}$ & Total Cost (\$) \\
\hline $100 \%$ & $13,402.43(100.00 \%)$ & $1813.91(100.00 \%)$ & $88,476.32(100.00 \%)$ \\
$150 \%$ & $13,412.42(100.07 \%)$ & $1844.76(101.70 \%)$ & $88,536.80(100.07 \%)$ \\
$200 \%$ & $13,419.44(100.13 \%)$ & $1866.03(102.87 \%)$ & $88,578.68(100.12 \%)$ \\
$250 \%$ & $13,424.83(100.17 \%)$ & $1882.20(103.76 \%)$ & $88,610.62(100.15 \%)$ \\
$300 \%$ & $13,429.21(100.20 \%)$ & $1895.20(104.48 \%)$ & $88,636.37(100.18 \%)$ \\
$350 \%$ & $13,432.89(100.23 \%)$ & $1906.06(105.08 \%)$ & $88,657.91(100.21 \%)$ \\
$400 \%$ & $13,436.07(100.25 \%)$ & $1915.36(105.59 \%)$ & $88,676.40(100.23 \%)$ \\
$450 \%$ & $13,438.86(100.27 \%)$ & $1923.50(106.04 \%)$ & $88,692.59(100.24 \%)$ \\
$500 \%$ & $13,441.33(100.29 \%)$ & $1930.72(106.44 \%)$ & $88,706.97(100.26 \%)$ \\
\hline & & & \\
\hline
\end{tabular}

Table A3. Effects of the changes in s depending on different distances by ship.

\begin{tabular}{cccc}
\hline & & $1000 \mathbf{k m}$ & \\
\hline Stock-Out & $Q$ & $Q_{r}$ & Total Cost (\$) \\
\hline $100 \%$ & $3479.04(100.00 \%)$ & $168.49(100.00 \%)$ & $12,643.91(100.00 \%)$ \\
$150 \%$ & $3479.10(100.00 \%)$ & $171.77(101.95 \%)$ & $12,652.37(100.07 \%)$ \\
$200 \%$ & $3479.17(100.00 \%)$ & $174.03(103.29 \%)$ & $12,658.20(100.11 \%)$ \\
$250 \%$ & $3479.21(100.01 \%)$ & $175.74(104.30 \%)$ & $12,662.63(100.15 \%)$ \\
$300 \%$ & $3479.26(100.01 \%)$ & $177.11(105.12 \%)$ & $12,666.19(100.18 \%)$ \\
$350 \%$ & $3479.30(100.01 \%)$ & $178.25(105.80 \%)$ & $12,669.17(100.20 \%)$ \\
$400 \%$ & $3479.34(100.01 \%)$ & $179.23(106.38 \%)$ & $12,671.72(100.22 \%)$ \\
$450 \%$ & $3479.36(100.01 \%)$ & $180.08(106.88 \%)$ & $12,673.95(100.24 \%)$ \\
$500 \%$ & $3479.40(100.01 \%)$ & $180.84(107.33 \%)$ & $12,675.92(100.25 \%)$ \\
\hline & & $5000 \mathbf{k m}$ & \\
\hline Stock-Out & $Q$ & $Q_{r}$ & Total Cost (\$) \\
\hline $100 \%$ & $4276.17(100.00 \%)$ & $894.86(100.00 \%)$ & $23,793.63(100.00 \%)$ \\
$150 \%$ & $4277.89(100.04 \%)$ & $909.32(101.62 \%)$ & $23,832.92(100.17 \%)$ \\
$200 \%$ & $4279.12(100.07 \%)$ & $919.31(102.73 \%)$ & $23,860.19(100.28 \%)$ \\
$250 \%$ & $4280.10(100.09 \%)$ & $926.91(103.58 \%)$ & $23,881.02(100.37 \%)$ \\
$300 \%$ & $4280.90(100.11 \%)$ & $933.03(104.27 \%)$ & $23,897.84(100.44 \%)$ \\
$350 \%$ & $4281.58(100.13 \%)$ & $938.14(104.84 \%)$ & $23,911.92(100.50 \%)$ \\
$400 \%$ & $4282.17(100.14 \%)$ & $942.52(105.33 \%)$ & $23,924.03(100.55 \%)$ \\
$450 \%$ & $4282.70(100.15 \%)$ & $946.36(105.76 \%)$ & $23,934.63(100.59 \%)$ \\
$500 \%$ & $4283.17(100.16 \%)$ & $949.76(106.14 \%)$ & $23,944.05(100.63 \%)$ \\
\hline
\end{tabular}


Table A3. Cont.

\begin{tabular}{cccc}
\hline & \multicolumn{3}{c}{$\mathbf{1 0 , 0 0 0} \mathbf{~ k m}$} \\
\hline Stock-Out & $Q$ & $Q_{r}$ & Total Cost (\$) \\
\hline $100 \%$ & $5162.24(100.00 \%)$ & $1822.46(100.00 \%)$ & $37,352.27(100.00 \%)$ \\
$150 \%$ & $5167.99(100.11 \%)$ & $1850.21(101.52 \%)$ & $37,430.25(100.21 \%)$ \\
$200 \%$ & $5172.11(100.19 \%)$ & $1869.41(102.58 \%)$ & $37,484.54(100.35 \%)$ \\
$250 \%$ & $5175.31(100.25 \%)$ & $1884.04(103.38 \%)$ & $37,526.07(100.47 \%)$ \\
$300 \%$ & $5177.95(100.30 \%)$ & $1895.83(104.03 \%)$ & $37,559.65(100.56 \%)$ \\
$350 \%$ & $5180.19(100.35 \%)$ & $1905.69(104.57 \%)$ & $37,587.81(100.63 \%)$ \\
$400 \%$ & $5182.12(100.39 \%)$ & $1914.15(105.03 \%)$ & $37,612.02(100.70 \%)$ \\
$450 \%$ & $5183.85(100.42 \%)$ & $1921.55(105.44 \%)$ & $37,633.25(100.75 \%)$ \\
$500 \%$ & $5185.38(100.45 \%)$ & $1928.13(105.80 \%)$ & $37,652.13(100.80 \%)$ \\
\hline
\end{tabular}

Table A4. Effects of the changes in s depending on different modal ratios between truck and rail.

\begin{tabular}{|c|c|c|c|}
\hline & \multicolumn{3}{|c|}{ Truck 1:9 Rail } \\
\hline Stock-Out & $Q$ & $Q_{r}$ & Total Cost (\$) \\
\hline $100 \%$ & $6481.89(100.00 \%)$ & $1813.75(100.00 \%)$ & $43,886.45(100.00 \%)$ \\
\hline $150 \%$ & $6487.81(100.09 \%)$ & $1842.09(101.56 \%)$ & $43,960.87(100.17 \%)$ \\
\hline $200 \%$ & $6492.05(100.16 \%)$ & $1861.68(102.64 \%)$ & $44,012.60(100.29 \%)$ \\
\hline $250 \%$ & $6495.34(100.21 \%)$ & $1876.59(103.47 \%)$ & $44,052.15(100.38 \%)$ \\
\hline $300 \%$ & $6498.03(100.25 \%)$ & $1888.61(104.13 \%)$ & $44,084.10(100.45 \%)$ \\
\hline $350 \%$ & $6500.31(100.28 \%)$ & $1898.66(104.68 \%)$ & $44,110.88(100.51 \%)$ \\
\hline $400 \%$ & $6502.30(100.31 \%)$ & $1907.27(105.16 \%)$ & $44,133.89(100.56 \%)$ \\
\hline $450 \%$ & $6504.04(100.34 \%)$ & $1914.81(105.57 \%)$ & $44,154.06(100.61 \%)$ \\
\hline \multirow[t]{2}{*}{$500 \%$} & $6505.60(100.37 \%)$ & $1921.50(105.94 \%)$ & $44,172.00(100.65 \%)$ \\
\hline & \multicolumn{3}{|c|}{ Truck 5:5 Rail } \\
\hline Stock-Out & $Q$ & $Q_{r}$ & Total Cost (\$) \\
\hline $100 \%$ & $10,161.55(100.00 \%)$ & $1805.96(100.00 \%)$ & $65,444.02(100.00 \%)$ \\
\hline $150 \%$ & $10,169.26(100.08 \%)$ & $1835.69(101.65 \%)$ & $65,510.62(100.10 \%)$ \\
\hline $200 \%$ & $10,174.70(100.13 \%)$ & $1856.20(102.78 \%)$ & $65,556.81(100.17 \%)$ \\
\hline $250 \%$ & $10,178.91(100.17 \%)$ & $1871.81(103.65 \%)$ & $65,592.07(100.23 \%)$ \\
\hline $300 \%$ & $10,182.33(100.20 \%)$ & $1884.37(104.34 \%)$ & $65,620.52(100.27 \%)$ \\
\hline $350 \%$ & $10,185.22(100.23 \%)$ & $1894.86(104.92 \%)$ & $65,644.33(100.31 \%)$ \\
\hline $400 \%$ & $10,187.71(100.26 \%)$ & $1903.85(105.42 \%)$ & $65,664.78(100.34 \%)$ \\
\hline $450 \%$ & $10,189.90(100.28 \%)$ & $1911.72(105.86 \%)$ & $65,682.69(100.36 \%)$ \\
\hline \multirow[t]{2}{*}{$500 \%$} & $10,191.86(100.30 \%)$ & $1918.70(106.24 \%)$ & $65,698.61(100.39 \%)$ \\
\hline & \multicolumn{3}{|c|}{ Truck 9:1 Rail } \\
\hline Stock-Out & $Q$ & $Q_{r}$ & Total Cost (\$) \\
\hline $100 \%$ & $12,820.27(100.00 \%)$ & $1811.62(100.00 \%)$ & $84,060.86(100.00 \%)$ \\
\hline $150 \%$ & $12,829.82(100.07 \%)$ & $1842.27(101.69 \%)$ & $84,122.42(100.07 \%)$ \\
\hline $200 \%$ & $12,836.53(100.13 \%)$ & $1863.40(102.86 \%)$ & $84,165.07(100.12 \%)$ \\
\hline $250 \%$ & $12,841.69(100.17 \%)$ & $1879.47(103.75 \%)$ & $84,197.59(100.16 \%)$ \\
\hline $300 \%$ & $12,845.88(100.20 \%)$ & $1892.39(104.46 \%)$ & $84,223.82(100.19 \%)$ \\
\hline $350 \%$ & $12,849.41(100.23 \%)$ & $1903.18(105.05 \%)$ & $84,245.76(100.22 \%)$ \\
\hline $400 \%$ & $12,852.45(100.25 \%)$ & $1912.43(105.57 \%)$ & $84,264.59(100.24 \%)$ \\
\hline $450 \%$ & $12,855.13(100.27 \%)$ & $1920.52(106.01 \%)$ & $84,281.08(100.26 \%)$ \\
\hline $500 \%$ & $12,857.52(100.29 \%)$ & $1927.70(106.41 \%)$ & $84,295.73(100.28 \%)$ \\
\hline
\end{tabular}


Table A5. Effects of the changes in $s$ depending on different modal ratios between truck and ship.

\begin{tabular}{cccc}
\hline & & Truck 1:9 Ship & \\
\hline Stock-Out & $Q$ & $Q_{r}$ & Total Cost (\$) \\
\hline $100 \%$ & $7256.52(100.00 \%)$ & $1696.14(100.00 \%)$ & $61,693.38(100.00 \%)$ \\
$150 \%$ & $7262.17(100.08 \%)$ & $1723.19(101.59 \%)$ & $61,761.47(100.11 \%)$ \\
$200 \%$ & $7266.18(100.13 \%)$ & $1741.88(102.70 \%)$ & $61,808.75(100.19 \%)$ \\
$250 \%$ & $7269.29(100.18 \%)$ & $1756.10(103.53 \%)$ & $61,844.88(100.25 \%)$ \\
$300 \%$ & $7271.84(100.21 \%)$ & $1767.55(104.21 \%)$ & $61,874.05(100.29 \%)$ \\
$350 \%$ & $7274.00(100.24 \%)$ & $1777.12(104.77 \%)$ & $61,898.49(100.33 \%)$ \\
$400 \%$ & $7275.86(100.27 \%)$ & $1785.33(105.26 \%)$ & $61,919.49(100.37 \%)$ \\
$450 \%$ & $7277.50(100.29 \%)$ & $1792.51(105.68 \%)$ & $61,937.88(100.40 \%)$ \\
$500 \%$ & $7278.99(100.31 \%)$ & $1798.89(106.06 \%)$ & $61,954.24(100.42 \%)$ \\
\hline & & Truck 5:5 Ship & \\
\hline Stock-Out & $Q$ & $Q_{r}$ & Total Cost (\$) \\
\hline $100 \%$ & $12,452.66(100.00 \%)$ & $1251.93(100.00 \%)$ & $150,112.66(100.00 \%)$ \\
$150 \%$ & $12,458.85(100.05 \%)$ & $1274.04(101.77 \%)$ & $150,156.82(100.03 \%)$ \\
$200 \%$ & $12,463.19(100.08 \%)$ & $1289.27(102.98 \%)$ & $150,187.36(100.05 \%)$ \\
$250 \%$ & $12,466.53(100.11 \%)$ & $1300.83(103.91 \%)$ & $150,210.62(100.07 \%)$ \\
$300 \%$ & $12,469.23(100.13 \%)$ & $1310.13(104.65 \%)$ & $150,229.37(100.08 \%)$ \\
$350 \%$ & $12,471.50(100.15 \%)$ & $1317.88(105.27 \%)$ & $150,245.04(100.09 \%)$ \\
$400 \%$ & $12,473.45(100.17 \%)$ & $1324.53(105.80 \%)$ & $150,258.49(100.10 \%)$ \\
$450 \%$ & $12,475.18(100.18 \%)$ & $1330.33(106.26 \%)$ & $150,270.26(100.10 \%)$ \\
$500 \%$ & $12,476.72(100.19 \%)$ & $1335.48(106.67 \%)$ & $150,280.71(100.11 \%)$ \\
\hline 5 & & Truck 9:1 Ship & \\
\hline Stock-Out & $Q$ & $Q_{r} \%$ & Total Cost (\$) \\
\hline $100 \%$ & $15,988.66(100.00 \%)$ & $837.88(100.00 \%)$ & $233,903.30(100.00 \%)$ \\
$200 \%$ & $15,994.20(100.03 \%)$ & $854.04(101.93 \%)$ & $233,930.70(100.01 \%)$ \\
$250 \%$ & $16,998.05(100.06 \%)$ & $865.13(103.25 \%)$ & $233,949.60(100.02 \%)$ \\
$300 \%$ & $16,003.39(100.09 \%)$ & $880.27(105.06 \%)$ & $233,975.52(100.03 \%)$ \\
$350 \%$ & $16,005.38(100.10 \%)$ & $885.89(105.73 \%)$ & $233,985.17(100.04 \%)$ \\
$400 \%$ & $16,007.10(100.12 \%)$ & $890.70(106.30 \%)$ & $233,993.44(100.04 \%)$ \\
$450 \%$ & $16,008.61(100.12 \%)$ & $894.90(106.81 \%)$ & $234,000.67(100.04 \%)$ \\
$500 \%$ & $16,009.95(100.13 \%)$ & $898.63(107.25 \%)$ & $234,007.09(100.04 \%)$ \\
\hline & & & \\
\hline
\end{tabular}

Table A6. Effects of the changes in $s$ depending on different modal ratios with rail and ship.

\begin{tabular}{cccc}
\hline & \multicolumn{3}{c}{ Rail 1:9 Ship } \\
\hline Stock-Out & $Q$ & $Q_{r}$ & Total Cost (\$) \\
\hline $100 \%$ & $13,779.90(100.00 \%)$ & $1703.77(100.00 \%)$ & $105,184.81(100.00 \%)$ \\
$150 \%$ & $13,789.50(100.07 \%)$ & $1733.08(101.72 \%)$ & $105,241.14(100.05 \%)$ \\
$200 \%$ & $13,796.22(100.12 \%)$ & $1753.27(102.91 \%)$ & $105,280.14(100.09 \%)$ \\
$250 \%$ & $13,801.40(100.16 \%)$ & $1768.62(103.81 \%)$ & $105,309.86(100.12 \%)$ \\
$300 \%$ & $13,805.60(100.19 \%)$ & $1780.96(104.53 \%)$ & $105,333.82(100.14 \%)$ \\
$350 \%$ & $13,809.11(100.21 \%)$ & $1791.26(105.14 \%)$ & $105,353.86(100.16 \%)$ \\
$400 \%$ & $13,812.16(100.23 \%)$ & $1800.09(105.65 \%)$ & $105,371.06(100.18 \%)$ \\
$450 \%$ & $13,814.82(100.25 \%)$ & $1807.81(106.11 \%)$ & $105,386.11(100.19 \%)$ \\
$500 \%$ & $13,817.21(100.27 \%)$ & $1814.66(106.51 \%)$ & $105,399.49(100.20 \%)$ \\
\hline
\end{tabular}


Table A6. Cont.

\begin{tabular}{cccc}
\hline & & Rail 5:5 Ship & \\
\hline Stock-Out & $Q$ & $Q_{r}$ & Total Cost (\$) \\
\hline $100 \%$ & $15,183.26(100.00 \%)$ & $1268.50(100.00 \%)$ & $171,755.83(100.00 \%)$ \\
$150 \%$ & $15,191.09(100.05 \%)$ & $1291.45(101.81 \%)$ & $171,796.77(100.02 \%)$ \\
$200 \%$ & $15,196.56(100.09 \%)$ & $1307.24(103.05 \%)$ & $171,825.05(100.04 \%)$ \\
$250 \%$ & $15,200.75(100.12 \%)$ & $1319.22(104.00 \%)$ & $171,846.59(100.05 \%)$ \\
$300 \%$ & $15,204.16(100.14 \%)$ & $1328.85(104.76 \%)$ & $171,863.93(100.06 \%)$ \\
$350 \%$ & $15,207.00(100.16 \%)$ & $1336.88(105.39 \%)$ & $171,878.43(100.07 \%)$ \\
$400 \%$ & $15,209.46(100.17 \%)$ & $1343.76(105.93 \%)$ & $171,890.86(100.08 \%)$ \\
$450 \%$ & $15,211.62(100.19 \%)$ & $1349.77(106.41 \%)$ & $171,901.74(100.08 \%)$ \\
$500 \%$ & $15,213.53(100.20 \%)$ & $1355.10(106.83 \%)$ & $171,911.39(100.09 \%)$ \\
\hline & & Rail 9:1 Ship & \\
\hline Stock-Out & $Q$ & $Q_{r}$ & Total Cost (\$) \\
\hline $100 \%$ & $16,450.04(100.00 \%)$ & $842.12(100.00 \%)$ & $237,993.76(100.00 \%)$ \\
$150 \%$ & $16,455.80(100.04 \%)$ & $858.41(101.93 \%)$ & $238,020.85(100.01 \%)$ \\
$200 \%$ & $16,459.81(100.06 \%)$ & $869.59(103.26 \%)$ & $238,039.52(100.02 \%)$ \\
$250 \%$ & $16,462.87(100.08 \%)$ & $878.06(104.27 \%)$ & $238,053.71(100.03 \%)$ \\
$300 \%$ & $16,465.35(100.09 \%)$ & $884.86(105.08 \%)$ & $238,065.13(100.03 \%)$ \\
$350 \%$ & $16,467.44(100.11 \%)$ & $890.53(105.75 \%)$ & $238,074.66(100.03 \%)$ \\
$400 \%$ & $16,469.22(100.12 \%)$ & $895.38(106.32 \%)$ & $238,082.83(100.04 \%)$ \\
$450 \%$ & $16,470.78(100.13 \%)$ & $899.61(106.83 \%)$ & $238,089.97(100.04 \%)$ \\
$500 \%$ & $16,472.16(100.13 \%)$ & $903.36(107.27 \%)$ & $238,096.31(100.04 \%)$ \\
\hline
\end{tabular}

Table A7. Effects of the changes in $s$ depending on different CVs of $X$ with truck and rail.

\begin{tabular}{cccc}
\hline & & CV 0.1 & \\
\hline Stock-Out & $Q$ & $Q_{r}$ & Total Cost (\$) \\
\hline $100 \%$ & $7140.52(100.00 \%)$ & $1379.43(100.00 \%)$ & $60,771.56(100.00 \%)$ \\
$150 \%$ & $7142.66(100.03 \%)$ & $1393.77(101.04 \%)$ & $60,805.93(100.06 \%)$ \\
$200 \%$ & $7144.18(100.05 \%)$ & $1403.64(101.76 \%)$ & $60,829.72(100.10 \%)$ \\
$250 \%$ & $7145.37(100.07 \%)$ & $1411.15(102.30 \%)$ & $60,847.86(100.13 \%)$ \\
$300 \%$ & $7146.34(100.08 \%)$ & $1417.18(102.74 \%)$ & $60,862.48(100.15 \%)$ \\
$350 \%$ & $7147.16(100.09 \%)$ & $1422.21(103.10 \%)$ & $60,874.71(100.17 \%)$ \\
$400 \%$ & $7147.87(100.10 \%)$ & $1426.53(103.41 \%)$ & $60,885.20(100.19 \%)$ \\
$450 \%$ & $7148.49(100.11 \%)$ & $1430.30(103.69 \%)$ & $60,894.39(100.20 \%)$ \\
$500 \%$ & $7149.05(100.12 \%)$ & $1433.64(103.93 \%)$ & $60,902.55(100.22 \%)$ \\
\hline & & CV 0.5 & \\
\hline Stock-Out & $Q$ & $Q_{r}$ & Total Cost (\$) \\
\hline $100 \%$ & $7786.46(100.00 \%)$ & $2705.91(100.00 \%)$ & $64,448.35(100.00 \%)$ \\
$150 \%$ & $7810.26(100.31 \%)$ & $2768.91(102.33 \%)$ & $64,621.19(100.27 \%)$ \\
$200 \%$ & $7827.20(100.52 \%)$ & $2812.58(103.94 \%)$ & $64,741.74(100.46 \%)$ \\
$250 \%$ & $7840.39(100.69 \%)$ & $2845.89(105.17 \%)$ & $64,834.12(100.60 \%)$ \\
$300 \%$ & $7851.17(100.83 \%)$ & $2872.75(106.17 \%)$ & $64,908.89(100.71 \%)$ \\
$350 \%$ & $7860.29(100.95 \%)$ & $2895.23(107.00 \%)$ & $64,971.62(100.81 \%)$ \\
$400 \%$ & $7868.22(101.05 \%)$ & $2914.53(107.71 \%)$ & $65,025.62(100.90 \%)$ \\
$450 \%$ & $7875.20(101.14 \%)$ & $2931.43(108.33 \%)$ & $65,072.97(100.97 \%)$ \\
$500 \%$ & $7881.40(101.22 \%)$ & $2946.44(108.89 \%)$ & $65,115.13(101.03 \%)$ \\
\hline & & &
\end{tabular}


Table A7. Cont.

\begin{tabular}{cccc}
\hline & \multicolumn{3}{c}{ CV 1.0 } \\
\hline Stock-Out & $Q$ & $Q_{r}$ & Total Cost (\$) \\
\hline $100 \%$ & $9046.77(100.00 \%)$ & $4489.01(100.00 \%)$ & $66,857.84(100.00 \%)$ \\
$150 \%$ & $9113.32(100.74 \%)$ & $4608.18(102.65 \%)$ & $67,165.07(100.46 \%)$ \\
$200 \%$ & $9160.77(101.26 \%)$ & $4690.96(104.50 \%)$ & $67,379.75(100.78 \%)$ \\
$250 \%$ & $9197.67(101.67 \%)$ & $4754.22(105.91 \%)$ & $67,544.46(101.03 \%)$ \\
$300 \%$ & $9227.87(102.00 \%)$ & $4805.30(107.05 \%)$ & $67,677.89(101.23 \%)$ \\
$350 \%$ & $9253.46(102.28 \%)$ & $4848.09(108.00 \%)$ & $67,789.91(101.39 \%)$ \\
$400 \%$ & $9275.66(102.53 \%)$ & $4884.85(108.82 \%)$ & $67,886.37(101.54 \%)$ \\
$450 \%$ & $9295.28(102.75 \%)$ & $4917.06(109.54 \%)$ & $67,971.03(101.67 \%)$ \\
$500 \%$ & $9312.81(102.94 \%)$ & $4945.70(110.17 \%)$ & $68,046.41(101.78 \%)$ \\
\hline
\end{tabular}

Table A8. Effects of the changes in $s$ depending on different CVs of $X$ with truck and ship.

\begin{tabular}{|c|c|c|c|}
\hline & \multicolumn{3}{|c|}{ CV 0.1} \\
\hline Stock-Out & $Q$ & $Q_{r}$ & Total Cost (\$) \\
\hline $100 \%$ & $6358.26(100.00 \%)$ & $1472.23(100.00 \%)$ & $42,856.21(100.00 \%)$ \\
\hline $150 \%$ & $6360.36(100.03 \%)$ & $1487.23(101.02 \%)$ & $42,893.43(100.09 \%)$ \\
\hline $200 \%$ & $6361.87(100.06 \%)$ & $1497.57(101.72 \%)$ & $42,919.21(100.15 \%)$ \\
\hline $250 \%$ & $6363.04(100.08 \%)$ & $1505.43(102.25 \%)$ & $42,938.87(100.19 \%)$ \\
\hline $300 \%$ & $6364.01(100.09 \%)$ & $1511.75(102.68 \%)$ & $42,954.73(100.23 \%)$ \\
\hline $350 \%$ & $6364.82(100.10 \%)$ & $1517.03(103.04 \%)$ & $42,968.00(100.26 \%)$ \\
\hline $400 \%$ & $6365.52(100.11 \%)$ & $1521.55(103.35 \%)$ & $42,979.39(100.29 \%)$ \\
\hline $450 \%$ & $6366.14(100.12 \%)$ & $1525.51(103.62 \%)$ & $42,989.37(100.31 \%)$ \\
\hline \multirow[t]{2}{*}{$500 \%$} & $6366.70(100.13 \%)$ & $1529.02(103.86 \%)$ & $42,998.23(100.33 \%)$ \\
\hline & \multicolumn{3}{|c|}{ CV 0.5} \\
\hline Stock-Out & $Q$ & $Q_{r}$ & Total Cost (\$) \\
\hline $100 \%$ & $7065.47(100.00 \%)$ & $2897.00(100.00 \%)$ & $47,038.95(100.00 \%)$ \\
\hline $150 \%$ & $7092.34(100.38 \%)$ & $2963.12(102.28 \%)$ & $47,231.06(100.41 \%)$ \\
\hline $200 \%$ & $7111.48(100.65 \%)$ & $3008.97(103.87 \%)$ & $47,365.16(100.69 \%)$ \\
\hline $250 \%$ & $7126.38(100.86 \%)$ & $3043.96(105.07 \%)$ & $47,467.97(100.91 \%)$ \\
\hline $300 \%$ & $7138.58(101.03 \%)$ & $3072.19(106.05 \%)$ & $47,551.23(101.09 \%)$ \\
\hline $350 \%$ & $7148.92(101.18 \%)$ & $3095.81(106.86 \%)$ & $47,621.10(101.24 \%)$ \\
\hline $400 \%$ & $7157.84(101.31 \%)$ & $3116.10(107.56 \%)$ & $47,681.25(101.37 \%)$ \\
\hline $450 \%$ & $7165.79(101.42 \%)$ & $3133.86(108.18 \%)$ & $47,734.03(101.48 \%)$ \\
\hline \multirow[t]{2}{*}{$500 \%$} & $7172.87(101.52 \%)$ & $3149.65(108.72 \%)$ & $47,781.02(101.58 \%)$ \\
\hline & \multicolumn{3}{|c|}{ CV 1.0} \\
\hline Stock-Out & $Q$ & $Q_{r}$ & Total Cost (\$) \\
\hline $100 \%$ & $8461.68(100.00 \%)$ & $4799.93(100.00 \%)$ & $50,049.44(100.00 \%)$ \\
\hline $150 \%$ & $8538.56(100.91 \%)$ & $4925.20(102.61 \%)$ & $50,392.49(100.69 \%)$ \\
\hline $200 \%$ & $8593.34(101.56 \%)$ & $5012.27(104.42 \%)$ & $50,632.24(101.16 \%)$ \\
\hline $250 \%$ & $8635.95(102.06 \%)$ & $5078.82(105.81 \%)$ & $50,816.18(101.53 \%)$ \\
\hline $300 \%$ & $8670.88(102.47 \%)$ & $5132.57(106.93 \%)$ & $50,965.20(101.83 \%)$ \\
\hline $350 \%$ & $8700.41(102.82 \%)$ & $5177.61(107.87 \%)$ & $51,090.32(102.08 \%)$ \\
\hline $400 \%$ & $8726.08(103.12 \%)$ & $5216.31(108.67 \%)$ & $51,198.05(102.29 \%)$ \\
\hline $450 \%$ & $8748.67(103.39 \%)$ & $5250.22(109.38 \%)$ & $51,292.60(102.48 \%)$ \\
\hline $500 \%$ & $8768.99(103.63 \%)$ & $5280.38(110.01 \%)$ & $51,376.79$ (102.65\%) \\
\hline
\end{tabular}


Table A9. Effects of the changes in $s$ depending on different CVs of $X$ with rail and ship.

\begin{tabular}{cccc}
\hline & & CV $\mathbf{0 . 1}$ & \\
\hline Stock-Out & $Q$ & $Q_{r}$ & Total Cost (\$) \\
\hline $100 \%$ & $13,625.74(100.00 \%)$ & $1396.46(100.00 \%)$ & $104,485.79(100.00 \%)$ \\
$150 \%$ & $13,630.22(100.03 \%)$ & $1412.08(101.12 \%)$ & $104,515.03(100.03 \%)$ \\
$200 \%$ & $13,633.36(100.06 \%)$ & $1422.81(101.89 \%)$ & $104,535.21(100.05 \%)$ \\
$250 \%$ & $13,635.76(100.07 \%)$ & $1430.95(102.47 \%)$ & $104,550.55(100.06 \%)$ \\
$300 \%$ & $13,637.70(100.09 \%)$ & $1437.47(102.94 \%)$ & $104,562.90(100.07 \%)$ \\
$350 \%$ & $13,639.34(100.10 \%)$ & $1442.92(103.33 \%)$ & $104,573.22(100.08 \%)$ \\
$400 \%$ & $13,640.74(100.11 \%)$ & $1447.58(103.66 \%)$ & $104,582.06(100.09 \%)$ \\
$450 \%$ & $13,641.97(100.12 \%)$ & $1451.65(103.95 \%)$ & $104,589.80(100.10 \%)$ \\
$500 \%$ & $13,643.06(100.13 \%)$ & $1455.26(104.21 \%)$ & $104,596.66(100.11 \%)$ \\
\hline & & CV 0.5 & \\
\hline Stock-Out & $Q$ & $Q_{r}$ & Total Cost (\$) \\
\hline $100 \%$ & $14,370.19(100.00 \%)$ & $2699.41(100.00 \%)$ & $107,049.65(100.00 \%)$ \\
$150 \%$ & $14,399.71(100.21 \%)$ & $2767.25(102.51 \%)$ & $107,184.25(100.13 \%)$ \\
$200 \%$ & $14,420.53(100.35 \%)$ & $2814.17(104.25 \%)$ & $107,277.78(100.21 \%)$ \\
$250 \%$ & $14,436.61(100.46 \%)$ & $2849.91(105.58 \%)$ & $107,349.27(100.28 \%)$ \\
$300 \%$ & $14,449.69(100.55 \%)$ & $2878.71(106.64 \%)$ & $107,407.02(100.33 \%)$ \\
$350 \%$ & $14,460.70(100.63 \%)$ & $2902.78(107.53 \%)$ & $107,455.40(100.38 \%)$ \\
$400 \%$ & $14,470.24(100.70 \%)$ & $2923.44(108.30 \%)$ & $107,496.98(100.42 \%)$ \\
$450 \%$ & $14,478.63(100.75 \%)$ & $2941.52(108.97 \%)$ & $107,533.41(100.45 \%)$ \\
$500 \%$ & $14,486.12(100.81 \%)$ & $2957.57(109.56 \%)$ & $107,565.80(100.48 \%)$ \\
\hline & & CV 1.0 & \\
\hline Stock-Out & $Q$ & $Q$ & Total Cost (\$) \\
\hline $100 \%$ & $15,465.01(100.00 \%)$ & $4491.70(100.00 \%)$ & $107,777.80(100.00 \%)$ \\
$150 \%$ & $15,530.23(100.42 \%)$ & $4619.24(102.84 \%)$ & $108,006.88(100.21 \%)$ \\
$200 \%$ & $15,576.41(100.72 \%)$ & $4707.70(104.81 \%)$ & $108,166.48(100.36 \%)$ \\
$250 \%$ & $15,612.21(100.95 \%)$ & $4775.22(106.31 \%)$ & $108,288.67(100.47 \%)$ \\
$300 \%$ & $15,641.46(101.14 \%)$ & $4829.69(107.52 \%)$ & $108,387.50(100.57 \%)$ \\
$350 \%$ & $15,666.13(101.30 \%)$ & $4875.28(108.54 \%)$ & $108,470.37(100.64 \%)$ \\
$400 \%$ & $15,687.53(101.44 \%)$ & $4914.44(109.41 \%)$ & $108,541.66(100.71 \%)$ \\
$450 \%$ & $15,706.36(101.56 \%)$ & $4948.72(110.17 \%)$ & $108,604.16(100.77 \%)$ \\
$500 \%$ & $15,723.17(101.67 \%)$ & $4979.19(110.85 \%)$ & $108,659.78(100.82 \%)$ \\
\hline & & & \\
\hline
\end{tabular}

\section{References}

1. World Trade Report 2015. Available online: https://www.wto.org/english/res_e/booksp_e/world_trade_ report15_e.pdf (accessed on 18 November 2016).

2. Sources of Greenhouse Gas Emissions. Available online: https://www.epa.gov/ghgemissions/sourcesgreenhouse-gas-emissions (accessed on 2 October 2016)

3. Solomon, S.; Qin, D.; Manning, M.; Chen, Z.; Marquis, M.; Averyt, K.B.; Tignor, M.; Miller, H.L. Contribution of Working Group I to the Fourth Assessment Report of the Intergovernmental Panel on Climate Change; Solomon, $\mathrm{S}$., Qin, D., Manning, M., Chen, Z., Marquis, M., Averyt, K.B., Tignor, M., Miller, H.L., Eds.; Cambridge University Press: Cambridge, UK; New York, NY, USA, 2017.

4. Ortolani, C.; Persona, A.; Sgarbossa, F. External cost effects and freight modal choice: Research and application. Int. J. Logist. Res. Appl. 2011, 14, 199-220.

5. Rai, D.; Sodagar, B.; Fieldson, R.; Hu, X. Assessment of $\mathrm{CO}_{2}$ emissions reduction in a distribution warehouse. Energy 2011, 36, 2271-2277.

6. Türkay, M. Environmentally conscious supply chain management. In Process Systems Engineering; Pistikopoulos, E.N., Georgiadis, M.C., Dua, V., Eds.; Wiley-VCH Verlag GmbH \& Co. KGaA: Weinheim, Germany, 2010; pp. 45-86.

7. Hua, G.; Cheng, T.C.E.; Wang, S. Managing carbon footprints in inventory control. Work. Pap. 2009, doi:10.2139/ssrn.1628953. 
8. Bonney, M.; Jaber, M.Y. Environmentally responsible inventory models: Non-classical models for a non-classical era. Int. J. Prod. Econ. 2011, 133, 43-53.

9. Wahab, M.I.M.; Mamum, S.M.H.; Ongkunaruk, P. EOQ models for a coordinated two-level international supply chain considering imperfect items and environmental impact. Int. J. Prod. Econ. 2011, 134, 151-158.

10. Bouchery, Y.; Ghaffari, A.; Jemai, Z.; Dallery, Y. Including sustainability criteria into inventory models. Eur. J. Oper. Res. 2012, 222, 229-240.

11. Moon, I.; Jeong, Y. J.; Saha, S. Fuzzy bi-Objective production-distribution planning problem under the carbon emission constraint. Sustainability 2016, 8, 798.

12. Battini, D.; Persona, A.; Sgarbossa, F. A sustainable EOQ model: Theoretical formulation and applications. Int. J. Prod. Econ. 2014, 149, 145-153.

13. Andriolo, A.; Battini, D.; Grubbström, R.W.; Persona, A.; Sgarbossa, F. A century of evolution from Harris's basic lot size model: Survey and research agenda. Int. J. Prod. Econ. 2014, 155, 16-38.

14. Digiesi, S.; Mossa, G.; Mummolo, G. Supply lead-time uncertainty in a sustainable order quantity inventory model. Manag. Prod. Eng. Rev. 2013, 4, 15-27.

15. Winebrake, J.J.; Corbett, J.J.; Falzarano, A.; Hawker, J.S.; Korfmacher, K.; Ketha, S.; Zilora, S. Assessing energy, environmental, and economic tradeoffs in intermodal freight transportation. J. Air Waste Manag. Assoc. 2008, 10, 142-149.

16. Dhooma, J.; Baker, P. An exploratory framework for energy conservation in existing warehouses. Int. J. Logist. Res. Appl. 2012, 15, 37-51.

17. Campo, K.; Gijsbrechts, E.; Nisol, P. Towards understanding consumer response to stock-outs. J. Retail. 2000, 76, 219-242.

18. Djankov, S.; Freund, C.; Pham, C.S. Trading on time. Rev. Econ. Stat. 2010, 92, 166-173.

(C) 2017 by the authors. Licensee MDPI, Basel, Switzerland. This article is an open access article distributed under the terms and conditions of the Creative Commons Attribution (CC BY) license (http:/ / creativecommons.org/licenses/by/4.0/). 